\title{
Review \\ Recent Advances on Waste Plastic Thermal Pyrolysis: A Critical Overview
}

\author{
Osman Y. Yansaneh and Sharif H. Zein *
}

check for

updates

Citation: Yansaneh, O.Y.; Zein, S.H. Recent Advances on Waste Plastic Thermal Pyrolysis: A Critical Overview. Processes 2022, 10, 332. https://doi.org/10.3390/pr10020332 Academic Editor: Anil K. Bhowmick

Received: 5 January 2022

Accepted: 2 February 2022

Published: 9 February 2022

Publisher's Note: MDPI stays neutral with regard to jurisdictional claims in published maps and institutional affiliations.

Copyright: (c) 2022 by the authors. Licensee MDPI, Basel, Switzerland. This article is an open access article distributed under the terms and conditions of the Creative Commons Attribution (CC BY) license (https:// creativecommons.org/licenses/by/ $4.0 /)$.
Department of Chemical Engineering, Faculty of Science and Engineering, University of Hull (UoH), Kingston upon Hull HU6 7RX, UK; o.yansaneh-2015@hull.ac.uk

* Correspondence: s.h.zein@hull.ac.uk; Tel.: +44-148-246-6753

\begin{abstract}
Post-consumer plastic management, otherwise termed waste plastic (WP) management, is a great challenge in today's world, mainly because of its characteristic biodegradation properties. The quantity of waste plastics correspondingly increases with the increase in demand for plastic use. Research has shown that this demand increases yearly. Most of these waste plastics include highdensity polyethylene (HDPE), low-density polyethylene (LDPE), polyethylene terephthalate (PET) and polystyrene (PS). Potentially, these wastes are a wealth, and studies have explored that pyrolysis is a reputable mechanism to accomplish this. In this critical review, an extensive investigation on waste plastics thermal pyrolysis (WPTP) is carried out. The factors that affect the product's yield and selectivity are discussed, and a comparative quality guarantee of WPTP is examined. This paper presents an assurance into the current findings of WPTP and reveals some common gaps and misconceptions surrounding this field, which are recommendable towards the support of further research work. The significant role of co-pyrolysis of plastics with biomass in this field is also emphasised, and a glimpse into the influence of mixed waste plastics in pyrolysis is presented.
\end{abstract}

Keywords: detailed review; waste plastics; environmental pollution; thermal pyrolysis; pyrolysis factors; future research needs

\section{Introduction}

Pyrolysis is one of the most popular thermo-chemical treatment (TCT) methods known today. This is believed to be due to their immense impacts on the environment and their operational output. In a review conducted by Al-Salem et al. [1], this is mentioned, implying that the renewed attention that pyrolysis continues to face in recent times is due to the several effective and environmental advantages it offers to today's overall energy demand and fuel scarcity. For the pyrolytic liquefaction of waste plastics to occur, waste plastic is needed as feedstock. These feedstocks are inarguably abundant with their quantity being directly proportional to their use in society, spanning over the years. Research has shown that the volume of waste plastics generated each year is projected to be growing at an approximate rate of $4 \%$ per year [2]. This growth rate is quite alarming for our environments, especially if the right management methods and/or strategies are not instituted and timely. In these collections of waste plastics, polyethene (PE), polystyrene (PS) and polypropylene (PP) are the most dominant in municipal waste plastics (MWPs) [3]. However, in a research work by Sophonrat et al. [4], polyethene tops the list among these common waste plastics and the rest of 'the other wastes', and with an estimated weight percentage ranging between 38 and $62 \mathrm{wt} \%$ of plastic materials. 'The other wastes' refers to things, such as paper and paper packages, cardboards, glass and garden wastes among related municipal wastes. As mentioned above, there has been keen interest in the pyrolysis method in recent years [5]. With reference to contemporary world, the research carried out by Ma et al. [5] was conducted approximately twenty years ago today. In their research, a conversion process of base-sample, polymethylsilsesquioxane (a silicon material) to a ceramic was established with the aid of pyrolysis. Some five years down the line, Singh and Ruj [3] used real MWPs to produce gas 
products as fuel materials with the aid of pyrolysis. The resulting pyrolytic products have immense high heating values (HHVs), and this is believed to be significantly influential in the energy power generation industry, and can sustainably complement the energy input required to run the same pyrolysis process. Thus, to date, the significance and interest associated with the pyrolysis method has undisputedly increased much more. In 2018, Fivga and Dimitriou [6] investigated waste plastic pyrolysis (WPP), a techno-economic valuation, to produce heavy fuel oil as raw materials needed by the petrochemical industry to support this claim. The pyrolysis study centred on Aspen HYSYS simulation for the modelling of the pyrolysis plant, a fluidised bed reactor, utilised for the flowsheet of the waste plastics conversion process. Furthermore, from a literature perspective, Beti and Ring [7] utilised the pyrolysis method to investigate the effect of temperature with regard to programmed temperature pyrolysis, an alteration to the standard method for qualitative and quantitative analysis of organic materials, such as oil, bitumen and kerogen, enshrined in rock samples. Beti and Ring [7] went on to share what the respective advantages and limitations of the temperatures of these programmed temperature pyrolyses might have, such as in their explorations and production processes. To date, we know pyrolysis to be a thermal degradation process consisting of long hydrocarbon chain materials being subjected to heat application, influenced by inert atmospheres [8]. If under the influence of a catalyst, the pyrolysis is said to be catalytic, but if in the absence of a catalyst, it is referred to as thermal pyrolysis. This basic description of pyrolysis is supported in work conducted by Zafar [9], in which it is highlighted that the process of thermal pyrolysis constitutes simultaneous reactions and successive reactions when a polymeric material is heated under inert conditions. This means that the process transforms non-recyclable plastics (NRPs) and recyclable ones alike into oil and some syngas, by thermal de-polymerisation at moderate temperatures and in the absence of or reduced oxygen. During this process, an external heat source is utilised and is usually provided by combustion of the syngas by-product in a separate combustion chamber, and then by transferring the heat of combustion to the pyrolysis reactor across a metal interface. Themelis and Mussche [10] depicted that the heating value of one ton of NRP equates to approximately 5.4 barrels of pyrolysis oil. Plastics can be partially oxidised to synthetic gas $\left(\mathrm{CO}+\mathrm{H}_{2}\right)$, which can then be synthesised chemically to methanol $\left(\mathrm{CH}_{4} \mathrm{OH}\right)$ [11]. As much as pyrolysis constitutes a chemical process, it is worth noting that this same process technically commences with mechanical preparation and related application processes, such as separation, cleaning or washing and drying, among others [9]. Impurities, such as metals, paper, glass, oil and even inert materials, are removed from waste plastic composites before the actual processing of the remaining wastes (plastics) in a pyrolysis reactor. Over the years and in recent times, immense research interest has been drawn towards waste plastics pyrolysis (or feedstock recycling) as elaborated earlier in this section. The waste plastic materials are recycled into basic petrochemicals, potential feedstock for virgin plastic production [12-14], and a range of other products. Al-Salem et al. [12] emphasised the environmental friendliness of pyrolysis compared to other municipal solid waste (MSW) treatment methods. In their review, the chemical recycling treatment method utilised with the waste plastics and polyolefins shared a more environmental solution. Pyrolysis proves the opportunity surrounding the conversion of MSW, non-recyclable plastics among other related residues into an eco-friendly energy, heat and related products [9], as misconstrued in other research work relating to the pyrolysis of polyvinylchloride (PVC) and/or PS waste plastics, discussed in detail in Section 4.1 below, 'The Impact of Feedstock'. Incineration, landfilling and pyrolysis are potentially among the common treatment methods used in MSW facilities. As mentioned above, the condition under which pyrolysis takes place is at an inert atmosphere, free from or limited oxygen presence, thereby discouraging the formation of dioxins in the reaction process. This eventually reduces carbon footprints in the processes and the resulting products by reducing the carbon monoxide $(\mathrm{CO})$ emission and $\mathrm{CO}_{2}[3,15,16]$. During pyrolysis, the long chain organic materials being treated are broken down into smaller, and hence, less complex structures with reference to the heat flow and pressure control [17]. Note that the 
reaction or process temperature and reaction time are also pivotal in pyrolysis. Generally, pyrolysis, for common waste plastics around us, commences at approximately $300{ }^{\circ} \mathrm{C}$ reaction temperature and for some thermosensitive resins, such as vinyl-based polymers, this even occurs at a much lesser temperature [18]. Nonetheless, in literature published by Zafar [9], the thermal degradation of waste plastics initiates in between a $350{ }^{\circ} \mathrm{C}$ and $550{ }^{\circ} \mathrm{C}$ reaction temperature and can climb up to $700{ }^{\circ} \mathrm{C}$ or more. The reaction temperature can impact the residence time. According to a conference paper by Figueroa et al. [19], the typical residence time of operation for this process is usually longer but with less intense heat application, thus resulting in a mixture of aromatic hydrocarbons with a molecular weight greater than benzene (classified as tars), gases and char. In another study by Singh and Ruj [3], the char yield decreased with an increase in reaction temperature. In their work, a continuous reduction in the amount of char was seen with the operating temperature increasing from $450{ }^{\circ} \mathrm{C}$ to $600{ }^{\circ} \mathrm{C}$. At an increased temperature, the waste plastic feedstock can quickly attain the gaseous phase, thereby limiting the quantity of solid residues (char). They further highlighted the incompetencies of other research work, yielding either no char in the first place or a significant amount of it. Williams and Slaney [20] also mentioned this. However, it is worth noting that Singh and Ruj [3] established an optimum temperature for pyrolysis, topical volume, the density of oil, wax percentage and pointing out the recovery duration to be $500{ }^{\circ} \mathrm{C}$ with nil wax production density (0.73). Comparably, this agrees with the work of Williams and Slaney, Miskolczi et al., Sharma et al. and Syamsiro et al. [20-23]. Despite this, the residual output of such char produced is a potential feedstock (fuel) for other petrochemical processes [1]. However, in the pyrolysis work by Singh and Ruj [3], the quantity of char production with virgin or simulated waste plastics, which turned out to be low as compared to the char derived from MWP. Thus, the formation of char is common with MWP as well as virgin or simulated waste plastics and, therefore, dominant with Pes, PETs and PPs pyrolysis [24].

Nonetheless, at relatively moderate decomposition temperatures ranging between 500 and $650{ }^{\circ} \mathrm{C}$, pyrolysis with waste plastics is normally associated with producing valuable tars, such as in liquid oils and waxes, with yields ranging from a weight percent of 76 to $79 \mathrm{wt} \%[25,26]$. PE is common among the various waste plastics used in such research work. However, Mastral et al. [26] laid emphasis on the impact of high decomposition temperatures (ranging from 640 through 730 to $850{ }^{\circ} \mathrm{C}$ ) and residence time (ranging from 0.64 to $2.6 \mathrm{~s}$ ) for HDPE, with the aid of a fluidised bed reactor to produce waxes, gases and oil. At $640{ }^{\circ} \mathrm{C}$, the highest yield in the products is attributed to waxes, while there was an increase in the temperature for the highest gas yield and an oil yield of less than $10 \mathrm{wt} \%$. Chars may be associated with pyrolysis processes. Normally, the chars formed will have to be cleaned. As such, it is not always the case with the process of pyrolysis being that the flue gas produced is mostly treated before its utilisation. It is worth noting that these flue gases, otherwise termed exhaust gases, mostly comprise of nitrogen. In pyrolysis, nitrogen can be used as a pungent gas, thus, fostering the elimination of pollutants in the flue gas during the pyrolytic process.

Pyrolysis is a prominent process with great potentials entailing the production of valuable petrochemical products sourced from organic materials (such as waste plastics), as well as process and pyrolytic material upgrade. In essence, it can ultimately reduce the reliability of petroleum/crude oil for energy. According to Butler et al. [27], the pyrolysis of main plastic materials, such as ethane, propane, naphtha and gas oil, were used to derive products, such as ethene, propene and benzene. Further into their work, the final/intermediate products of PE, such as antifreeze, polyester fibres, foam, soaps and detergents; PP, such as fibres, foams, cumene (IP), $\mathrm{C}_{4}$ alcohols, oligemers, soaps and detergents; and styrene, such as polyurethanes, were produced. Furthermore, pyrolysis is environmentally friendly, providing an alternative solution to landfilling, incineration and greenhouse reduction, such as $\mathrm{CO}_{2}$ emissions. Syamsiro et al. [23], applied sequential pyrolysis on MWP to attain the fuel oil of gasoline and diesel yields. This means that, in pyrolysis, a range of petrochemical products are attainable depending on the assigned operating parameters, such as reaction 
or operating temperatures, reaction time and feedstock, and different types of pyrolysis are associated with these. For example, there is a form of pyrolysis that only involves heat application called thermal pyrolysis, and there is another in which catalysts are used. Catalysts are those substances that speed up a reaction process. However, the scope of this literature review does not cover catalysts or catalytic pyrolysis, but rather the baseline of pyrolysis, thermal pyrolysis. Nevertheless, the necessary recommendations to support and boost thermal pyrolysis for efficient scaling processes, better products, advanced chemical reaction processes, among other key components surrounding waste plastic management (WPM) are deliberated on in this paper. By and large, waste plastics can be combined with other feedstock materials other than plastics in a pyrolysis process named co-pyrolysis. Thermal pyrolysis essentially serves as the base of pyrolysis. Both co-pyrolysis (the fundamental) and thermal pyrolysis are discussed in detail in the immediate below subsections, providing a quick reference for further research work surrounding this field. This innovation, including an assurance attached to current findings of waste plastic thermal pyrolysis, WPTP, as well as a glimpse into the impacts mixed waste plastics have on pyrolysis are discussed. The co-pyrolysis of waste plastics with biomass and pyrolysis in general are also shared in this paper. Some common gaps and misconceptions surrounding this field are also revealed. This will help to enhance the progressiveness beyond the current work and facilitate a better accuracy in further and/or future research work and eventually real-life applications, such as the environmental friendliness of pyrolysis and it being a sustainable solution to waste plastics. Additionally, the objective of this review paper also depicts the limitations associated with thermal pyrolysis, which are major concerns in the industrial world. Thus, this can contribute to supporting and assuring future chemical engineering work or related research needs surrounding catalytic pyrolysis, which are dominant in the industrial world. Consequently, this work is essentially a simplification of a collection of thermal pyrolysis research work, mostly recent, being reviewed and referenced here, and showcasing the increased interest in pyrolysis treatment methods.

\subsection{Thermal Pyrolysis Process}

To date (the idea surrounding the catalysis of thermal pyrolysis), thermal pyrolysis has been a common pyrolysis type, which involves the waste plastic upgrade and related recycling purposes upon heat application and under inert atmosphere. The process involves heat application of the feedstock, in which temperatures could range from $400-600{ }^{\circ} \mathrm{C}$, a temperature range that is fairly the same as the $350-550{ }^{\circ} \mathrm{C}$ range proposed by Zafar [9]. According to their report, the operating temperature associated with the thermal degradation of organic constituents found in MSW can go up to $700{ }^{\circ} \mathrm{C}$ or $800{ }^{\circ} \mathrm{C}$ under inert atmospheres. As mentioned here, the process occurs under the influence of inert conditions for the thermal breakdown of waste plastics into liquid and other products. Plastics thermally degrade at a significantly higher temperature ranging from $400-450{ }^{\circ} \mathrm{C}$ [28] to $700-800{ }^{\circ} \mathrm{C}$ [9]. However, this process does not utilise catalysts, so a relatively high temperature and energy consumption is involved. As such, operating temperatures associated with thermal pyrolysis can go up to $900{ }^{\circ} \mathrm{C}$, as justified in an experimental pyrolysis investigation on PE, PS and PP waste plastics to gas and liquid hydrocarbons carried out by Demirbas [29]. This pyrolysis process is referred to as thermal or combustion (heat) recycling of waste plastics. Generally, the heat is scarcely regained in combustion processes. Inarguably, high energy or temperature input is known to impact the cost and even product quality. Liquid products obtained from thermal pyrolysis typically constitute higher boiling point-range hydrocarbons, as emphasised by Demirbas [29]. Further processing, such as fractional distillation or the incorporation of a catalyst, is eventually required to optimise thermal pyrolytic products into valuable oils and related useful products.

Regarding product quality yield, gaseous products acquired in thermal pyrolysis require additional refining processes to enhance their useful application as operating fuel products [30]. The issue surrounding heat loss is much more felt when dealing with mixed waste plastics because they constitute low thermal conductivity. Nonetheless, the 
characteristic products of these wastes are also dependent on the nature of the waste plastics and the process conditions that might be involved. For instance, Lee and Shin and Marcilla et al. [31,32] showed that in mixed waste plastics, the pyrolysis of PE constitute high proportions, yields and to a greater extent, unstable, heavy compounds with a high viscosity termed as low-grade yields. Furthermore, Aguadoet al. and Blazso [33,34] established that a high percentage of 1-alkenes and dialkenes constitute the yield associated with the pyrolytic, non-catalytic degradation of PE. Thus, just as much as the catalytic recycling of waste plastics can be a major alternative fuel source route, the thermal recycling counterpart can also be economically and environmentally influential when viewed from the economic and environmental aspects, respectively [35].

Generally, pyrolysis treatment mechanisms consist of a feeding section that handle the feedstock material. In the kettle-type reactor case shown in Figure 1 below, the feedstock is placed in the space where the mixer operates. Such feedstocks do not necessarily require pre-treatment methods, reactor unit assembly and product collection vessels that contain separation lines for the products as per their chemical properties. The mixer plays a significant role in this by ensuring primary readiness of the plastics for the actual pyrolysis process. In the work conducted by McCaffrey [36], depicted in Figure 1, the feedstock (plastic) heats up with the support of the heating mantle, thereby positioning the waste plastic feed into an enhanced readiness for the pyrolysis. The source-power is provided by an HP motor. The molten plastic is mixed with the aid of the mixer for an optimal thermal reaction. To prevent any incorporation of oxygen, the reactor is kept under a nitrogen atmosphere during the experiment. Figure 1 shows a typical pyrolysis setup but for a kettle-type reactor. The nitrogen serves as a purging substance, thus, not necessarily considered as a factor in the pyrolysis.

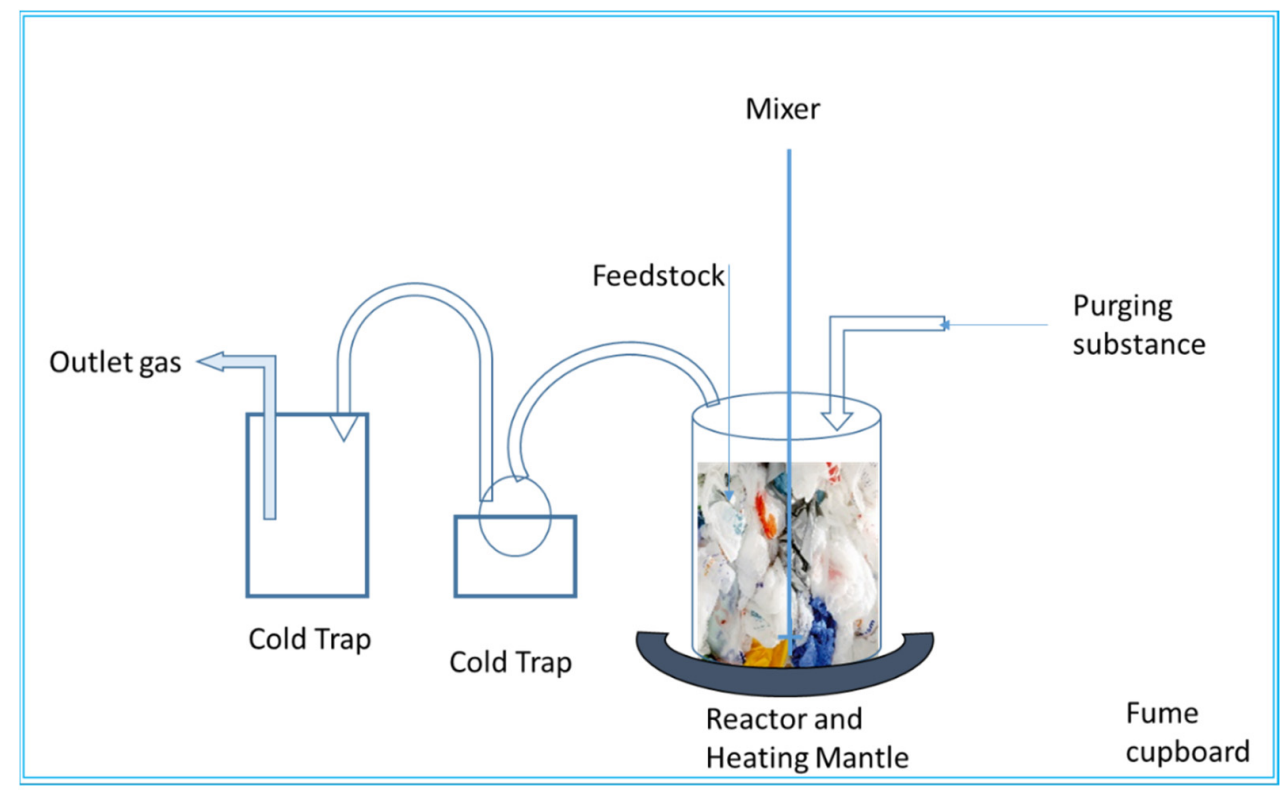

Figure 1. A basic pyrolysis setup (kettle-type reactor) (adapted from [36]).

In summary, thermal pyrolysis is construed to have some environmental problems with regards to waste plastic recycling, especially with the residence time. Consequently, additional attention is necessary for using this treatment method [37]. Furthermore, the hydrocarbon chains constituting a thermal pyrolysis yield are longer than those associated with catalytic pyrolysis. As such, the conditions responsible for the further decomposition of these long-chain hydrocarbons, in which case the boiling points for these materials can be reduced drastically for an optimised product yield [33] and reaction time, are exempted in thermal pyrolysis. Moses [38] experimented catalytic pyrolysis to produce diesel oil that matches the specifications conventional diesel using mixed waste plastics 
of low-density polyethene (LDPE) and high-density polyethene (HDPE). Silica-alumina synthesised catalysts is used on the baseline process of thermal pyrolysis to achieve this, together with the application of sodium carbonate, $\mathrm{Na}_{2} \mathrm{CO}_{3}$ to minimise emissions of dioxins in the atmosphere. The behaviour of catalyst applications on WPTP is emphasised in the work done by Marcilla et al. [39], to support this. The impacts catalysts have on pyrolysis is among the core reasons that positioned thermal pyrolysis as the fundamental process of pyrolysis. However, and as mentioned in the Introduction section, the scope of this paper will not cover catalytic pyrolysis. The limitation linked with thermal pyrolysis is largely considered greatly pivotal when it comes to industrial-scale operations. The role of a catalyst (catalytic pyrolysis) to turn this limitation around and augment thermal pyrolysis yield quantity and quality is highly recommended for real-world applications. Thus, the need for nearby installation of thermal pyrolysis plants to locations of catalytic pyrolysis plants is greatly significant and immensely recommended for economic, safety and environmental parameters, and the optimisation of thermal pyrolytic products.

\subsection{Co-Pyrolysis and Mixed Waste Plastics}

This is otherwise termed as the pyrolysis of a mixture of two or more feedstocks (waste plastics in this case and another material, say used oil or biomass) in the absence of hydrogen or hydrogen pressure [40]. Co-pyrolysis can take a thermal form, or it can be supported catalytically, if need be, to produce further useful products applicable in a wide variety of applications. This means that, with co-pyrolysis, a range of different materials used as feedstocks can be treated in a single process to investigate their behaviour, including acquiring their best output as a mixture. A notable application of this in the petrochemical industry includes the production of sustainable biofuels and other valuable hydrocarbons. However, this is typical for the case wherein biomasses are combined with coal [40]. Nonetheless, co-pyrolysis with a mixture of waste plastics or waste plastics (PVC and/or PS) that have embedded additives that seriously impact the environment can as well yield a range of products as reported in recent studies [41-46]. Some of these products include hydrogen chloride or hydrogen $\left(\mathrm{HCl}\right.$ or $\left.\mathrm{H}_{2}\right)$, diesel oil, gasoline, styrene monomers, fuel gas, and wax among other common pyrolytic products. Mansur et al. [44] catalytically pyrolysed mixed waste polyethylenes (LDPE and HDPE) with the support of volcanic ash as catalyst to produce liquid fuel. The mechanism of co-pyrolysis being associated with waste plastics is one of the radical interactions, significant to the synergistic effects, which, according to researchers, have shown to be hardly noticeable [47-49]. This implies that the process constitutes at least a lone electro that is in one way or the other critical to the coactive effects associated with the process, but whose influence is more or less invisible. It is a simple but effective, thus, efficient method of oil-upgrade which, according to Chen et al. and Guan et al. [50,51], can produce valuable pyrolytic fuel-oil and with even less coke formation. Another significance associated with co-pyrolysis is that it does not use solvents to enhance the process, as this could have been costlier than the pyrolytic product acquired [52]. Significant among the benefits of co-pyrolysis is the nexus with the method oil-upgrade, which has been shown, in the past, to be system and environmentally friendly than those of traditional pyrolysis ones. Kositkanawuth et al. [53] pointed out that the co-pyrolysis of biomass with waste plastics has successfully favoured better oil quality and quantity and with no adverse effect to the operating system. Generally, the operating conditions and parameters are imminent to obtain optimal results from a pyrolytic process, just as they are typical in co-pyrolysis. In fact, research has shown that there are variances in the operating conditions of single plastics to that of mixed plastics. This is also the case with co-pyrolysis due to the diverse boiling point temperatures of the respective materials it may constitutes. Operating conditions, such as feedstock ratio, pyrolysis pressure and temperature, reforming temperature, residence time and water injection flow rates, have continued to be experimentally researched for optimal operating conditions. Zhao and Yan [54] emphasised related operating conditions, such as feedstock ratio, pyrolysis temperature, reforming temperature and water injection flow rate, 
regarding product and yield optimisation in power generation. The need for optimising operating conditions is extensively valuable since one kind of plastic has, for instance, a different heating or pyrolysis temperature (no matter how minimal). As such, mixing two or more different waste plastic types will affect the overall heating temperature and reaction/residence time, among other key factors. This is because the various waste plastic kinds have varying melting points or heating temperatures. More details on the heating temperature and heating rate, and residence time associated with common categories or conditions of pyrolysis are discussed below in Sections 2.3 and 2.4, respectively. However, research conducted in the past has established that the co-pyrolysis of mixed polymeric materials yields higher oil quality and quantity, far more than those obtained from pyrolysis of single hydrocarbon materials [55-57]. Yang et al. [56] further showcased that the all-out oil relative yield for the co-pyrolysis of LDPE and biomass residue was attained at $600{ }^{\circ} \mathrm{C}$; compared to single pyrolysed LDPE, a clear distinction was revealed of how high the optimum temperature is. Similar to the case concerning the heating temperature, other operating conditions, such as feedstock ratio, pyrolysis temperature, reforming temperature and water injection flowrate, are being examined experimentally to find the respective optimal operating conditions. In the case associated with the pyrolysis of mixed waste plastics, it is imperative to understand that the feeds are sourced from MSW as well as post-consumer wastes and polyolefins (POs). This process arouses immense attention for the utilisation of these wastes by valorisation. It allows a high yield of fuels and raw materials to be obtained for the benefit of the petrochemical industry. With reference to Zhao and Yan [54], for the co-pyrolysis study of waste plastics, about $10 \mathrm{mg}$ of waste plastic samples was utilised at a heating rate of $10^{\circ} \mathrm{C} / \mathrm{min}$ under atmospheric conditions ranging from room temperature to approximately $800^{\circ} \mathrm{C}$ reaction temperature. This temperature was kept stable for 10 minutes before being lowered, thereby leading to the production of hydrogen, a method favoured by $\mathrm{Wu}$ et al. [42]. In another research work, pyrolytic conditions, such as heating rate, temperature and residence time, which favour a mass distribution of products [8] via the thermal pyrolysis of mixed waste plastics, was believed to be obtained from a complex free-radical mechanism.

In summary, co-pyrolysis enhances fuel oil optimisation and the process sync with eco-friendly scenarios. The overall heating temperature when dealing with mixed waste plastics is increased to above the average heating temperature of single plastics. This is carried out to accommodate and enhance the heating and melting of other plastics of higher heating temperatures in the mixture of plastics. As highlighted earlier in this sub-Section, each kind of waste plastic has a different heating temperature (operating condition) to the other, and thus some constitute higher heating temperatures than others. The degradation of PVC plastics in a mixture with other waste plastic kinds is a typical instance whereby other waste plastics will be in their molten state at a time when the dehydrochlorination of PVC is only taking place. This stage is typically a pre-treatment stage and can be handled by the mixer, such as in a kettle-type reactor, as discussed in Section 1.1. At this stage of the chemical reaction, the actual polymeric material will not already be in a molten state. This same characteristic property of PVC, which is due to the presence of the vinyl or hydrochloride $(\mathrm{HCl})$ in them, was pointed out in work conducted by Miranda et al. [58], and explained further in Section 4.1 ('The Impacts of Feedstock').

\section{Common Influential Factors of Waste Plastic Thermal Pyrolysis}

Fundamentally, the process steps for pyrolysis as well as its adjoining factors are significant to the general application of pyrolysis. Thus, with thermal pyrolysis being the basis of any pyrolysis process, such factors influence the process and eventually the outcome (products) in one way or the other. Inasmuch as most studies emphasise the effects of thermal pyrolysis temperature, the heating rate and chemical composition of feedstock with reference to the product yield, the general essence of factors affecting pyrolysis need not be overemphasised considering their overwhelming significance. Common among other factors include the reactor type, residence time and pressure, as discussed below. 
Many research works have been conducted around these factors, and many modifications and further developments are being carried out on these factors. To emphasise the great impact associated with pyrolysis, as recent as the year 2021, Li et al. [59] shared the effects of two of these factors (feedstock and pyrolysis temperature), the impact they have on biochar on the promotion of hydrogen yield via ethanol-type fermentation application. The process steps attached to pyrolysis include, but are not limited to, waste plastic accumulation, pre-treatment, shredding, pyrolysis, condensation and refining. The first three steps are largely mechanical, as highlighted in both Sections 1.1 and 1.2, except for pre-treatment, which may take a chemical approach, such as treating the feedstock in a pool of molten wax for the attainment of reduced viscosity prior to the main pyrolysis reaction.

Factors affecting plastic thermal pyrolysis, including the products of pyrolysis, have been depicted in various research work over the years. Reputable among these works are those conducted by Jung et al. and Zhang et al. [60,61], in which they investigated the influence of pyrolysis temperature stretching from $200{ }^{\circ} \mathrm{C}$ to $800{ }^{\circ} \mathrm{C}$. Banik et al., Gai et al., Hassan et al. and Mandal et al. [62-65] looked into both pyrolysis temperature and feedstock as pyrolysis factors, and Zhao [66] showcased the effect of pyrolysis temperature, residence time and heating rate associated with a range of waste plastics, such as $\mathrm{PP}$, polycarbonate (PC) and high impact polystyrene (HIPS). As mentioned earlier, the significance of the factors affecting plastic pyrolysis is glued and targeted to the desired product yields and the pyrolysis process in general. These factors influence the molecular structure of pyrolytic products. The major factors include the chemical composition of the feedstock under investigation, reactor type, cracking or decomposition temperature and heating rate, residence time and operating pressure.

\subsection{Chemical Composition of the Feedstock}

This is one of the most significant factors affecting pyrolysis. Section 2.3-('Decomposition Temperature and Heating Rate') throws light on the most important factors of plastic pyrolysis. According to Brandrup et al. [67], the recycling of feedstock is among the greatest challenges in plastic recycling technology. To date, a range of technologies have been well exhibited and many more are being developed. Furthermore, research has shown that the effects sustained from mono-plastics are unique from those which can be enhanced from a mixture, typical of the case of co-pyrolysis, as explained in Section 1.2 ('Co-pyrolysis'), in which mixed polymeric wastes enhance higher fuel yields and other related petrochemical products $[51,55,56]$. The major component of this uniqueness is characteristic of the chemical structure of the feedstock. In research conducted by Sun et al. [68], it was established that the proportion of hydrogen, $\mathrm{H}$, one of two of the major constituents of plastics, shrank in all kinds of biochars, triggered by the elimination of moisture content and thus, dehydrogenation. Furthermore, upon the completion of the pyrolysis, the content of nitrogen, $\mathrm{N}$, in coffee grounds, shrunk, but an increase was observed in corn stalk. Similarly, for PVC feedstock, the composition comprised of $\mathrm{HCl}$ /vinyl chloride, an impurity, and this is a source for the pyrolytic yield of hydrogen and other fuel energies. Kim [43] pyrolytically experimented with PVC feedstock to produce bioenergy through both a thermodynamic and kinetics study that revealed the production of bioenergy as a promising way to go.

Buekens [18] showcased three groups of plastics. From these groups, the first, a catalytic or peroxide-initiated polymerisation of monomer(s), happens to be among the most desirable groups of plastics for the purpose of feedstocks for pyrolysis [18]. Thus, the quality of plastic-derived fuels is dependent largely on the process and the feedstock. The diesel-range products in LDPE-derived fuels constitute similar linear alkane chains as those found in conventional diesel. In addition to this, additives, otherwise referred to as impurities, could be attached to these feedstocks as contaminants, leading to a negative influence on the feedstock performance, and hence poor product yields. Fundamentally, the feedstock is a significant factor, if not the most significant of all, and with it (waste plastic) being chemically recycled into monomers, a mixture of chemicals or conversion 
into fusion gas or reducing gas called fuels or other useful products are attainable [18] with the aid of the reactor type that may be used in the pyrolysis.

\subsection{Reactor Type}

The type of reactor utilised in pyrolysis is just as significant as the fuel yield [38]. Nonetheless, as mentioned earlier, other factors are also significant to the product yield percentage and fineness. In a study performed by Buekens [18], the selection of the reactor type is principally based on technical considerations, primarily its feed and residue handling characteristics and heat transfer. The selecting of a reactor is a key approach towards the mechanics of pyrolysis and is pivotal to product delivery. This is consequently explained by the fact that the following two steps take effect from the moment waste plastic is inputted into the reactor:

1. Fusion of the waste plastics.

2. Pyrolysis of the fused waste plastics.

With reference to step one, a non-stop feeding system is permissible for controlled pyrolysis. Hence, the need for improvement on this step is feeding into the reactor using different reactors [33,69]. Free-fall input is, at most times, used for the feeding of feedstocks into the reactor through its hopper or as the case may be, and as further discussed in Section 4.2.1. Separating the above two steps fosters the minimisation of secondary product formation, such as methane, char and even liquid (polycyclic aromatic hydrocarbons, PAHs) [70]. With the different reactors used for the experiment, including screw reactors, fluidised beds, conical spouted beds and even spouted bed reactors, solid material particles were made use of, coated with the fused plastics, thereby facilitating the heat and mass transfer between the plastics and the gas. Free-fall reactor is another notable reactor type, which Ellens [71] utilised to produce biofuels. In this work, a modern central composite design of the experiments was carried out, leading to the optimisation of the reactor. As mentioned in the sub-Section above ('Chemical Composition of Feedstock'), the feedstock (polymeric materials) utilised in pyrolytic processes are often subjected to pre-treatments and related procedures before they are put into the reactors and related mechanisms. Many processes proposed scenarios wherein the polymer is first scattered in a salt bath or quenched in a pool of molten polymer or wax to lessen the viscosity of the meltdown [18]. Furthermore, other processes are believed to recommend the utilisation of the exceptional heat transfer and combining properties of fluidised bed, thermal or even catalytic reactors. The application of an extruder is a similar practical example of this. The extruder basically serves as a pre-treatment mechanism that can be linked to the reactor for an optimal pyrolysis process.

Fluidised bed reactors are among the notable reactors known in today's chemical industry, especially regarding the processes associated with solid elements. According to Zafar [9], fluidised bed furnaces are among the most used pyrolysis reactors in the chemical industry, as well as rotary hearth furnaces and rotary kilns. A major reason for this is the nature by which they are built, a continuous feeding system [1], and their high heating capabilities [26]. Pandey et al. [72] used a fluidised bed reactor in their pyrolysis of waste plastics to produce environmentally friendly products. It was showcased that fluidised bed reactors are one of the most reputable reactors utilised in the continuous conversion process of waste plastics pitching towards operational optimisation. However, the conical spouted bed reactor has shown a more vigorous movement of solid particles than in that of bubbling fluidised bed reactors. With reference to many citations by authors, this stimulates the minimisation of the defluidisation problems of volatile sand melted plastic melting coating, influencing the fusion of the waste plastics and pyrolysis of the fused waste plastics.

\subsection{Decomposition Temperature and Heating Rate}

The decomposition, otherwise termed cracking temperature, and heating rate in pyrolysis are as significant as the process of pyrolysis itself. Temperature in this context refers to external heat/thermal application. This cracking or reaction temperature can 
vary due to other factors, such as the type of waste plastic feedstock and the desired product. For example, Singh and Ruj [3] utilised a reaction temperature of $450-600{ }^{\circ} \mathrm{C}$ to yield gaseous products from PE, PP, PS and PET as waste plastic feedstock, whereas in the work conducted by Zafar [9], it was 350-800 ${ }^{\circ} \mathrm{C}$ for bio-oil production using MSW as feedstock. Regarding the literature review by Gao [73], the reaction temperature with PE is emphasised as the most vital factor that inclined the whole pyrolysis process. However, this reaction temperature can vary even for similar reactors and feedstock materials. The reason for the difference in temperature depicted in different studies for the same reactor type and feedstock composition is reported to be due to the variance in the position of the temperature sensor of the reactors [73]. Another study conducted by Buekens [18], proved that temperature is the most vital functional factor associated with pyrolysis. It establishes both the rate of thermal disintegration and the stability of feedstock and products yielded upon the completion of the reaction. This means that there must be some cracking or degradation in the first instance for pyrolysis to occur. Heat and thus the cracking temperature are the key parameters in this process. Cracking or the decomposition temperature is the point at which the degradation of the polymers (plastic in this case) takes effect, but with varying pyrolytic impacts with respect to the state of the product. López et al. [46] proved that temperature strongly affects the characteristics of pyrolytic liquids and to a lesser extent in gas and solid properties. With reference to a work conducted by Singh and Ruj [3], an increment in temperature favours an increase in oil yield in plastic pyrolysis. In fact, with this rise in the oil yield, the polymeric aromatic components of the MPW also increase in formation. Generally, with an increase in temperature, the oil density decreases. In a study by Mansur et al. [44], the breakdown of the plastic materials into chemicals of low carbon chains (say C8-C9) was partly, yet significantly, supported by the influence of heat and temperature. The heat and/or temperature in pyrolysis can adopt a range of low, moderate or high temperatures to produce new materials. For example, a high temperature $\left(>600^{\circ} \mathrm{C}\right)$ and both vacuum and yield dilution facilitate the manufacture of basic insignificant gaseous molecules [18]. However, a low temperature $\left(<400{ }^{\circ} \mathrm{C}\right)$ and expanded pressure, point to additional viscous liquid yields, elevated rates of pyrolysis, an immense coking capability and extra minor products and dehydrogenation [18]. It is worth noting that the plastic liquefaction of oil mainly consists of cyclic chemical compounds. Additionally, cyclic compounds are known to constitute higher boiling points than their acyclic or open-chain isomers. This means if such an oil is to be converted into a more refined oil or related valuable yields, further cracking is required, hence more heat energy and residence time. Table 1 depicts a summary of the significance of cracking temperatures and heating rates on pyrolysis and their corresponding pyrolytic yields.

Table 1. A summarised tabular representation of the conditions of pyrolysis, influence of cracking temperatures and heating rate and their potential products (adapted from [74]).

\begin{tabular}{cccc}
\hline Conditions of Pyrolysis & Cracking Temperature $\left({ }^{\circ} \mathbf{C}\right)$ & Heating Rate & Derived Products \\
\hline Slow carbonisation & $450-600$ & Very low & Charcoal \\
\hline Slow pyrolysis & $450-600$ & $10-100 \mathrm{~K} / \mathrm{min}$ & Gas, oil and char \\
\hline Fast pyrolysis & $550-650$ & Up to $1000 \mathrm{~K} / \mathrm{s}$ & Gas, oil and (char) \\
\hline Flash pyrolysis & $450-900$ & Up to $10,000 \mathrm{~K} / \mathrm{s}$ & Gas, oil and (char) \\
\hline
\end{tabular}

The cracking temperature for both the slow carbonisation and slow pyrolysis is the same, but the resulting product types are different: charcoal and gas, and oil, respectively. This is subject to the influence of the different heating rates utilised in the various pyrolyses. Char is seen as derived products from almost all the types of pyrolysis previously outlined. It is imperative to note that the formation of char is voluminous with municipal plastic wastes, MPW being that the feed materials sourced from MSW consist of extra particles and related impurities $[24,75]$. This study was verified by utilising virgin or simulated plastic waste pyrolysis, in which case the quantity of char produced was typically low. Impurities 
and related contamination factors, such as additives, could be attributed to this difference in the results [24]. Additional details are shared in the 'Introduction Section' in this paper. Wang et al. [76] found that biochars prepared at an increased pyrolysis temperature heighten the productions of hydrogen, $\mathrm{H}$, and established that the $\mathrm{pH}$ cushioning volume is the central component of biochar promoting fermentative hydrogen production. Unlike biochar, other petrochemical wastes, such as plastics in general, require a higher pyrolysis temperature to increase the degree of carbonisation [59]. Hydrogen, $\mathrm{H}$, and carbon, $\mathrm{C}$, are the most predominant constituent elements of these petrochemical wastes. Additionally, aside from $\mathrm{H}$ and $\mathrm{C}$ formations, gaseous products (also constituents of $\mathrm{H}$ and $\mathrm{C}$ ) are the other reputable materials acquired. Singh and Ruj [3] reported the effect and formation of gaseous products with respect to the experimental tests, demonstrating that an increase in $\mathrm{H}_{2}$ was perceived upon a temperature increment with a decrease in low molecular weight hydrocarbons, HCs. This seems to be in agreement with Buekens [18], whose work revealed that the increase in temperature significantly influences the relative stability of a variety of products, including the kinetics and physical conditions of the reacting mixture. Nonetheless, the initial stage of pyrolytic reactions was solidly affected by the spectre of additives, such as pigments, plasticisers and stabilisers. As such, a medium temperature ranging between $400-500{ }^{\circ} \mathrm{C}$ was chosen, and the plastics were in a liquid phase, whereas 'gas phase' processes made way for liquid polymer films, spreading across the grains of the fluidised bed pyrolysis reactor type [18]. These additives in the feedstock that affect the initial stage of the pyrolysis process do so not only after the decomposition of temperature and heating rate, but also the residence time as well to allow complete reaction.

\subsection{Residence Time}

Residence time, otherwise referred to as reaction time, is another pivotal factor of plastic pyrolysis. Research has shown that the required residence time is determined primarily by decomposition or the reaction temperature. Short residence time is believed to aid the creation of primary products, such as monomers, while the creation of more thermodynamically stable products, such as $\mathrm{H}_{2}, \mathrm{CH}_{4}$, aromatics and carbon are linked to long residence times [18]. Monomers of plastics can include, but are not limited to, the organic compounds of ethylene, propylene, styrene, vinyl chloride, formaldehyde and even phenol [77]. The formation of these monomers, including other hydrocarbons, such as propane, and n-butane is influenced by the residence time of volatiles in a reactor [3]. As mentioned earlier, there is a strong relationship between reaction temperature and residence time. Singh and Ruj [3] pointed out this relationship in their work, in which the effect of residence time is portrayed to be large at higher temperature process requirements, leading to the production of heavier hydrocarbons in gas and in oil than in wax, with $\mathrm{PE}$ as feedstock. This is one of those conditions under which no carbon monoxide (CO) and/or carbon dioxide $\left(\mathrm{CO}_{2}\right)$ is noticeable, but there is certainly a noticeable increase in $\mathrm{H}_{2}$ production. The production of $\mathrm{CO}, \mathrm{CO}_{2}$ and $\mathrm{H}_{2}$ gases are associated with waste plastic pyrolysis as oxidation occurs during pyrolysis. This is referred to as oxidative pyrolysis, giving rise to the production of non-condensable gases, such as $\mathrm{CO}$ and $\mathrm{CO}_{2}$. One other significant effect of this condition is the recovery time of non-condensable gases, which is perceived to be a smaller amount at increased temperatures, but with a generally increased yield upon increasing the operating temperature. This is technically in alignment with thermal pyrolysis. However, optimising this approach with the aid of a catalyst has experimentally shown that the yield of such non-condensable materials can increase exponentially. A reputable example for this scenario can be seen in a work carried out by Singh and Ruj and Gao [3,73], in which they revealed that with the application of a ZSM-5 catalyst, the percentage of the non-condensable gases is boosted from $17 \% \mathrm{w} / \mathrm{w}$ to approximately $60 \% \mathrm{w} / \mathrm{w}$ by adding $10 \% \mathrm{w} / \mathrm{w}$ NKC -5 into the PE feedstock. The residence time can be strongly identified from the positions at which the classification of pyrolysis is analysed. The classification of pyrolysis is dependent on the residence time or heating rate. According to Naresh et al. [78], this implies that pyrolysis can be slow carbonisation, 
slow pyrolysis, fast pyrolysis or flash pyrolysis, as is illustrated in Table 1. Technically, each of these classifications has a different definition of what residence time is. Slow pyrolysis (and batch process), which is the conventional pyrolysis, depicts residence time as the time duration from when the waste plastic begins to heat up to that when the products are attained [18]. This means that a slow heating rate and long residence time are associated with this class of pyrolysis, and it enhances the yield of the carbonisation process, resulting in a greater yield of tar and char. With a longer residence time, a further conversion process of the primary products into secondary ones (such as light molecular weight hydrocarbons and non-condensable gases), which are more thermally stable [79-81], is achievable. A long residence time is known to foster light hydrocarbon yields [73], unlike a short residence time, in which case the volatiles minimise the formation of secondary products, such as methane, liquid and char $[69,82]$; fast, or otherwise referred to as a continuous pyrolysis process, defines this as the contact time from the point the plastic touches the hot surface until the end of the reaction [83]. Table 2 summaries the conditions of pyrolysis, residence time as well as their consequent products. For both fast and flash pyrolyses, the yield of char is known to be inconsistent. However, there will always be gas and oil yields, as shown in Table 2.

Table 2. A summarised tabular representation of pyrolysis conditions and potential products (adapted from [74]).

\begin{tabular}{ccc}
\hline Conditions of Pyrolysis & Residence Time & Derived Products \\
\hline Slow carbonisation & Over $24 \mathrm{~h}$ & Charcoal \\
\hline Slow pyrolysis & $10-60 \mathrm{~min}$ & Gas, oil and char \\
\hline Fast pyrolysis & $0.5-5 \mathrm{~s}$ & Gas, oil, (char) \\
\hline Flash pyrolysis & $<1 \mathrm{~s}$ & Gas, oil, (char) \\
\hline
\end{tabular}

Aside from the heating rate, temperature is another key factor that works in line with residence time. The initial table (Table 1) showcases the effect of temperature and heating rate on the various residence times outlined in Table 2. All these put together favour the derived products shown in Table 2. The longer residence time of over $24 \mathrm{~h}$ gives rise to the formation of charcoal, as emphasised in the slow carbonisation condition of pyrolysis.

Therefore, a low heating rate and long residence time tend to increase the energy input. Nonetheless, with reference to current studies, fast or flash pyrolyses at high temperatures with very short residence times are the ideal pyrolyses processes for the yielding of oily products [84]. This is clearly represented in Table 2, especially for the case in which the residence times fall in the range of $0.5-5 \mathrm{~s}$ or even less.

However, if the slow pyrolysis reactor is in a closed system, the residence time can be seen as a complex parameter that can be controlled directly [74]. Nevertheless, changing other process parameters, such as carrier gas flow rate, feeding rate of the feedstock and product discharge rate, can promote residence time control.

\subsection{Pressure}

Pyrolysis processes and their subsequent products are both influenced by their operating pressures. Operating pressures in pyrolysis can either be low or high. A low pressure (under vacuum, or in the presence of inert diluent) favours the production of primary products, including monomers, whereas complex liquid fractions are associated with high pressures [18]. With a high pressure, the boiling point of pyrolytic products attain an increment. This increment fosters a pressurised environment, a condition in which heavy hydrocarbons are further pyrolysed rather than vaporised at a given operating temperature [85]. Essentially, as explained in the work of Sato and Sakata [85], more heat energy is permissible for the purpose of increased hydrocarbon cracking with respect to a pyrolysis system subjected to a pressurised reaction. The issue of a pressurised system is associated with a high pressure, in effect. It is worth looking at Figure $2 \mathrm{a}$, which is a 
graphical representation of Gay Lussac's Law, to put this into context. As such, with an increase in pressure, the system becomes compressed, implying less occupying space for the gases (non-condensable gases in this case), giving rise to a reduction in their average molecular weight due to their increased speed. In the computed Table 3 below, Sato and Sakata [85] show this effect.

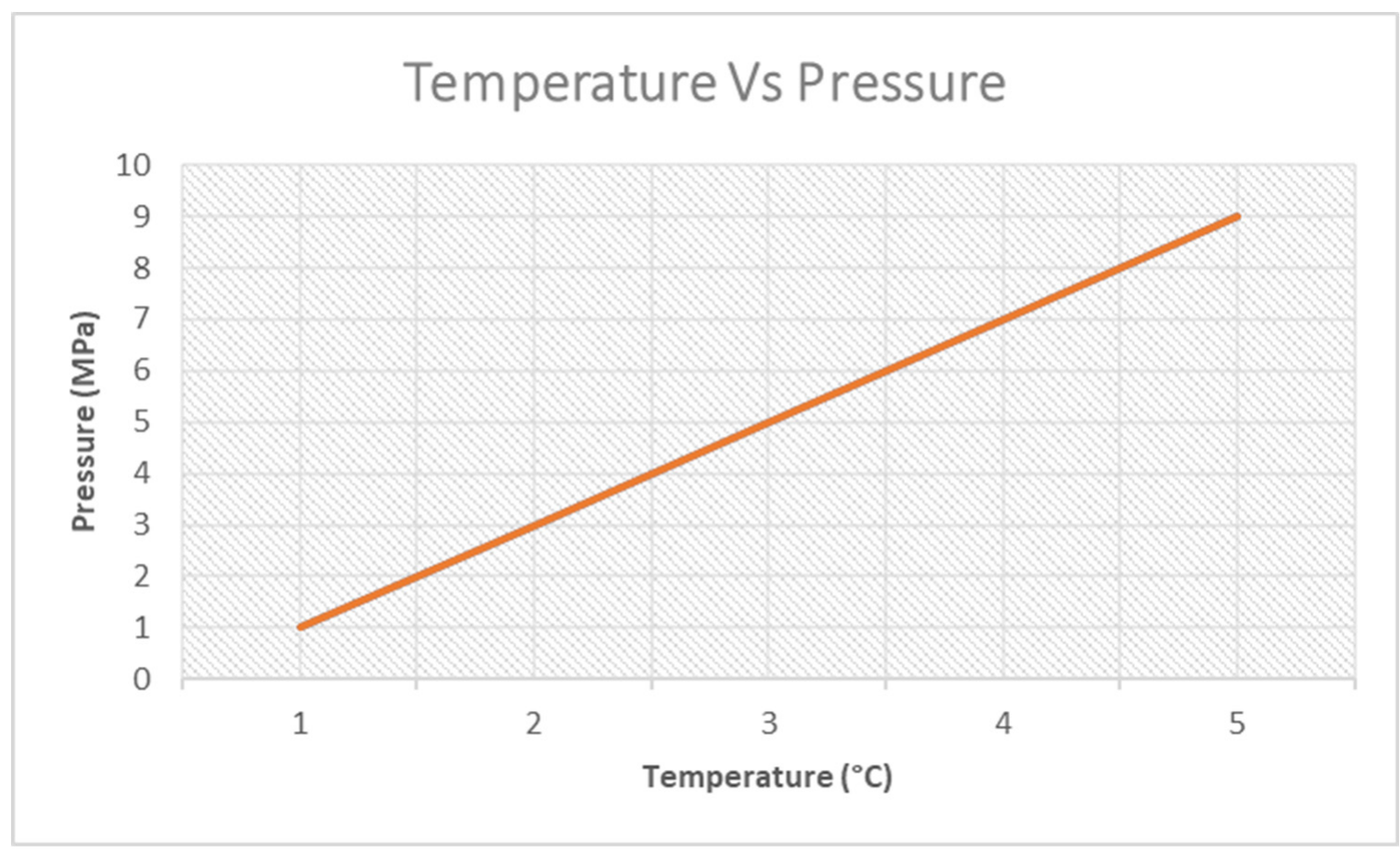

(a)

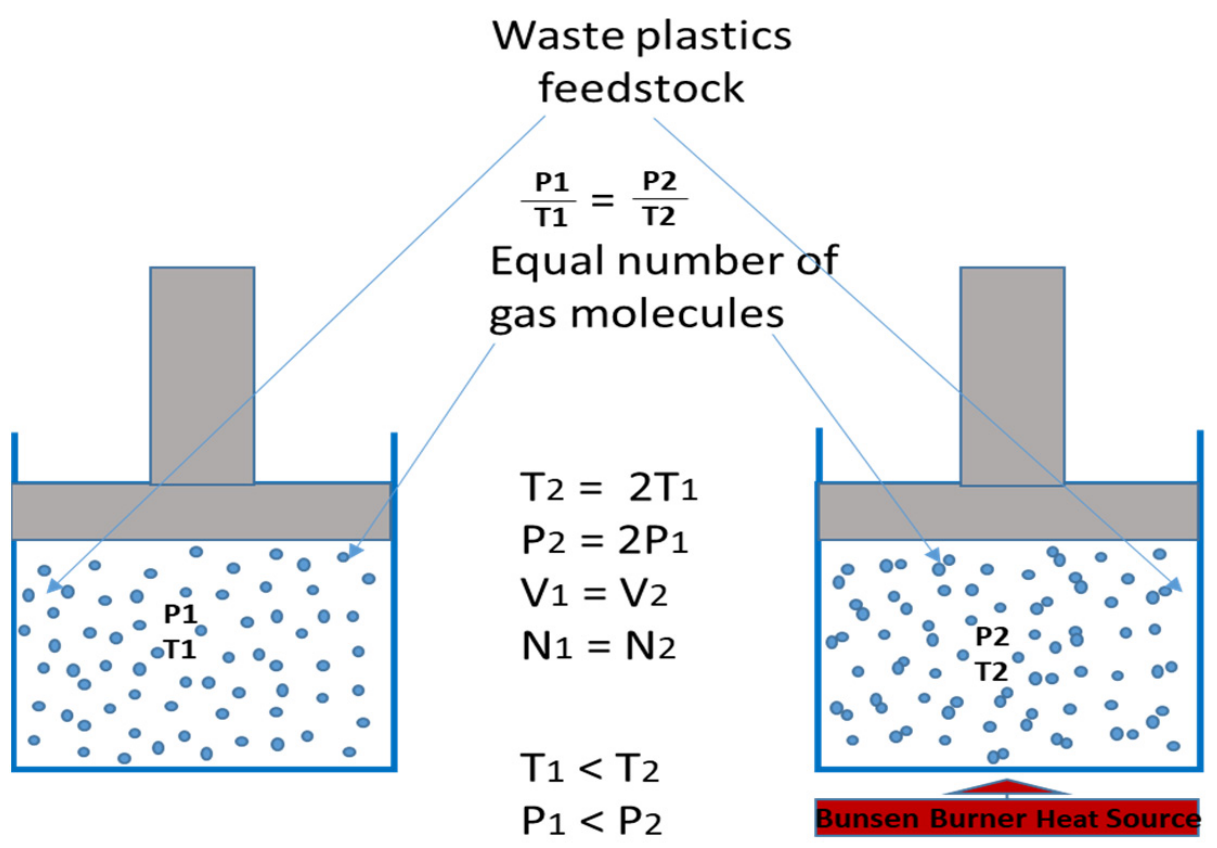

(b)

Figure 2. (a) A graphical representation of Gay Lussac's Law, (b) A schematic of Gay Lussac's Law (adapted from [86]). 
Table 3. Relationship of pressure with respect to the different temperatures for gas yield (adapted from [85]).

\begin{tabular}{llllll}
\hline \multicolumn{7}{c}{ Gas Yield/wt vs. Degeneration Pressure/Mpa } \\
\hline$@ 410^{\circ} \mathrm{C}$ & 6.4 vs. 0.1 & 7.0 vs. 0.2 & 9.0 vs. 0.4 & 10.4 vs. 0.6 & 13.0 vs. 0.8 \\
\hline$@ 420^{\circ} \mathrm{C}$ & 4.4 vs. 0.1 & 5.4 vs. 0.2 & 6.0 vs. 0.4 & 7.3 vs. 0.6 & 8.0 vs. 0.8 \\
\hline$@ 430^{\circ} \mathrm{C}$ & 4.3 vs. 0.1 & 4.4 vs. 0.2 & 5.2 vs. 0.4 & 6.0 vs. 0.6 & 6.2 vs. 0.8 \\
\hline$@ 440^{\circ} \mathrm{C}$ & 3.8 vs. 0.1 & 4.0 vs. 0.2 & 4.8 vs. 0.4 & 5.0 vs. 0.6 & 5.8 vs. 0.8 \\
\hline
\end{tabular}

Furthermore, the role of temperature with respect to pressure is depicted; the relationship is directly proportional. With a temperature increase, the pressure increases (pressurised), thereby increasing the motion of the gas molecules (gas yield for the case of pyrolysis).

With reference to Gao [73], it is revealed that at a high pressure, the yield of noncondensable gases increases, but with a decrease in the liquid yield. Lower molecularweight gases are typical examples of such non-condensable gases, and they include gases that include $\mathrm{CO}$ and $\mathrm{CO}_{2}$. Partial vacuum, otherwise termed negative pressure, is a key factor in plastic pyrolysis as this ensures the minimisation of oxidation reactions, and further hastens the removal of gaseous vapours pitching towards the reduction of secondary reactions' incidence in the process chamber of a pyrolytic reactor [48]. Oxidation is bound to occur during plastic pyrolysis or even during an oxidative pyrolysis, due to the presence of oxygen in the structure of plastics. Generally, nitrogen, $\mathrm{N}_{2}$, can be used as the purging substance for the removal of air and related contaminants in the chamber, thus it does not necessarily participate in the reaction process. This is essential since pyrolysis constitutes oxidation; oxygen, water, or related reagents are barred. Furthermore, the elimination or the formulation of a barrier towards undesirable by-products is realised. As a result, during this process, the waste plastic is gently 'cracked' at relatively low temperatures to enhance the primarily straight chain aliphatic hydrocarbons with a minimal formation of by-products. Thermal pressure is known to be a significant player, especially in the context of plastic recycling. According to a Central Pollution Control Board report, it takes between 2-3 times only as per virgin plastic material recycling, since plastic materials deteriorate due to the thermal pressure on every recycling process [87].

However, high temperatures and heating rates, low pressures and residence times facilitate the formation of major products. Equally, long residence times lead to a prevalence of other steady products, such as methane and cooking gases [18].

The graphical representation in Figure 2a is a theoretical display of Gay Lussac's Law, which asserts that the pressure of a given quantum of gas at ideal conditions held at a constant mass and volume is directly proportional to the temperature involved [88]. In the context of pyrolysis, the heating of the system paves the way to increased temperatures. This engages the molecules of the waste plastic feedstock in an excited state, increasing their impacts on the reactor walls. Hence, a pressurised reaction system is established. This then gives rise to the increased motion of the gas molecules, as depicted in Figure $2 b$ and supported by Gao and Sato and Sakata $[73,85]$. Figure $2 b$ gives a schematic glance into what Gay Lussac's Law is, with waste plastics as feedstock materials. The reaction chamber with the heat source $\left(\mathrm{T}_{2}<\mathrm{T}_{1}\right)$ shows an increased motion of the gas molecules of the feedstock, hitting one another, thereby giving rise to a more pressurised system, and, hence, a gaseous yield.

\section{Quality Guarantee of Waste Plastic Pyrolysis and Petroleum Products with Emphasis on Diesel: A Brief Comparative Analysis}

With reference to the New Zealand diesel regulations, 18 requirements are made use of in the diesel comparison with that of plastic-derived fuels. These 18 requirements are grouped into thermodynamic properties, component distribution, performance properties and flow properties. Benzene, toluene and xylene (BTX) aromatics can be grouped under 
plastic-derived fuels. Jung et al. [89] produced BTX aromatics from pyrolignic waste PE and PP plastics with the support of a fluidised bed reactor. The investigation centred on feed rate, decomposition temperature, and the influence of the fluidised bed on the product range. These properties align with two (thermodynamic properties and component distribution) of the four groups of the 18 requirements for diesel comparison with that of plastic-derived fuels as stated above. These same two groups can be linked to the hydrocarbon yields of mixed plastics as reported by Sophonrat et al. [90]. Distinct treatments are utilised in relation to the two product distributions of hydrocarbons and oxygenated materials obtained. The third group, performance properties can be connected to their study as per the circular economic benefits (useful industrial materials, chemicals and/or energy recoveries) of the products. The two products including the plastic-derived (cetane-indexbased) product of hydrocarbons are produced via multi-step pyrolysis with reference to their various reaction temperatures that encompass the thermodynamic property group as explained above. From the regulation for commercial types of diesels, the cetane number or cetane index are the most significant thermodynamic properties, as they depict the auto-ignition conditions of the fuel [91]. Fuel density and the distillation range are used for the cetane number calculation. These parameters can be found as part of the regulatory requirements; hence all three properties (cetane index, fuel flow and fuel performance) are essential for the property makeup of diesel.

Fuel flow property is another crucial aspect in the quality assurance of pyrolysis products and conventional petroleum fuels, and other petrochemical yields. Seemingly, this is next in line in order of significance after the cetane number. The fuel flow properties involve viscosity, pour point, flash point, cold filter plugging and cloud point.

Fuel performances involve oxidation stability, colour, particulate, lubricity, filter blocking tendency and copper corrosion [91]. Copper corrosion mainly indicates sulphur additives in the diesel. However, there may be miscellaneous properties, such as sulphur (see Table 4), cited by Uzoejinwa et al. [52], and water content attached to the diesel. Such additives, such as the sulphur found in these conventional diesel fuel products, are known to negatively impact fuel performance in engine systems, the engine system itself and, thus, the overall life span of the machine. However, with reference to the diesel products obtained from plastic pyrolysis, these setbacks are considered as insignificant since they do not constitute in the yield. Furthermore, Table 4 gives a summary of the elemental compositions and HHVs of the various waste plastics comparable with those of gasoline (petrol) and diesel. In a work conducted by Scheirs and Kaminsky [92], the alkene content in LDPE-derived products was much higher than that in conventional diesel, known to be responsible for the decrease in fuel storage stability.

Nonetheless, the American Society for Testing and Materials (ASTM) system is the fundamental definition for product specifications and measurement methods, applicable for most fragments of fuels and industrial products. ASTM D 6751-02 sets forth the specifications that must be met for pyrolysis and fatty acidy ester production. Koppolu et al. [93] established that the specification for 'biodiesel fuel' or the 'B100' product that meets the specification will perform effectively as a compression ignition fuel, either as a sole B100 or in blends with any petroleum-derived diesel fuel, such as in the case for pyrolytic diesel fuels.

Essentially, the constituent elemental compositions for each of the waste plastics in comparison to either gasoline or diesel are approximately the same, but with a minimal difference in the sulphur (S) content, which can be taken care of in the pyrolysis of plastics. This highlights the fact that waste plastics can indeed be pyrolysed into liquid fuels or petrochemical products. It also proves that waste plastics are products of crude oil or petroleum. The HHV for PE is nearly equivalent to that of gasoline and diesel in the size of $46 \mathrm{MJ} / \mathrm{kg}$. Going by this, PE being a significant feedstock in high yields of pyrolytic liquid fuels, as explained in Section 3, concludes the liquid-fuel potential associated with PEs, and as supported by a range of experimental literatures. 
Table 4. Elemental compositions and HHVs of various waste plastics compared with gasoline (petrol) and diesel.

\begin{tabular}{|c|c|c|c|c|c|c|c|}
\hline Waste Plastics & C (\%) & H (\%) & O (\%) & N (\%) & $\mathrm{S}(\%)$ & HHV (MJ/kg) & References \\
\hline PE & $80.50-85.40$ & $14.30-15.50$ & $0.03-3.90$ & $0.00-0.30$ & $0.00-0.30$ & 46.1 & {$[89,94,95]$} \\
\hline PS & $86.40-92.70$ & $7.40-8.50$ & $0.00-1.30$ & $0.00-6.10$ & $0.00-0.10$ & $39.00-42.10$ & {$[89,95,96]$} \\
\hline PP & $85.1-86.50$ & $12.90-14.40$ & $0.00-0.20$ & 0 & $0.00-0.5$ & $37.60-46.40$ & {$[89,95]$} \\
\hline Gasolinea $^{\mathrm{y}}$ & 82.68 & 15.13 & 2.09 & 0.0016 & 0.0006 & 45.8 & $\begin{array}{c}\text { Summer gasoline } \\
\text { in the Republic of } \\
\text { Korea. }\end{array}$ \\
\hline Diesela $^{\mathrm{y}}$ & 86.58 & 13.41 & 0.01 & 0.0005 & 0.0005 & 45.96 & $\begin{array}{c}\text { [8]; summer diesel } \\
\text { in the Republic of } \\
\text { Korea. }\end{array}$ \\
\hline
\end{tabular}

y Summer gasoline and diesel in the Republic of Korea [52].

\section{Active Commercial Plastic Pyrolysis Processes and Technologies}

As many solutions are emergent on the management and useful handling of waste plastics and related polymeric wastes around the world, many parts of the Earth have been and are continually developing pyrolysis mechanisms and other chemical reaction systems to enhance this. Thus, WPP plants have been developed and built in many countries. In research conducted by Fivga et al. [6], an industrial-scale pyrolysis plant was modelled for production yield optimisation and economic viability of waste plastics into heavy fuel-oil alternatives, in which the net present value (NPV) and pay-out period (PO) of the plant were calculated technically to attain this. The calculated model is in support of the literature reported by Liu et al. and Gao [45,73]. Aboulkas et al. [97] developed and utilised a special laboratory fluidised bed pyrolysis reactor to produce gasoline and styrene monomers with $\mathrm{PE}$ as feedstock. However, two key factors concerning the effectiveness and use of pyrolysis plants are tied to the effects of the feedstock composition and the adjoining technology. In Section 2.1, a detailed investigation is carried out on the chemical composition of feedstock. The remainder of the subsections of Section 2 can be grouped under 'technology', as the second of two factors surrounding the effectiveness and utilisation of pyrolysis processes or pyrolysis plants. Thus, feedstock and the technology utilised are two of the most significant factors encompassing the effectiveness and utilisation of pyrolysis processes/plants.

\subsection{The Impacts of Feedstock}

The impact of feedstock, when it comes to pyrolysis or any other related chemical processes, need not to be overemphasised. With reference to Section 2.1 and as reported by Brandrup et al. [67], feedstock or its recycling are among the biggest issues when it comes to plastic recycling. Some of these waste plastics have unique fillers and additives from other waste plastics, such as PVC and PS. PVCs, just as the case with PSs, are believed to affect the thermal degradation and related technologies of waste plastics. These additives give rise to a greater energy input and hence higher temperatures or longer residence times to allow the reaction to attain completion. This is because of their constituent of hydrochloride $\mathrm{HCl}$ /vinyl chloride for the case of PVC, which is evidently harmful to health (human, animals and plants) and to fuels [43]. Styrene and benzene for the case of PS, are also toxic substances with a carcinogenic and neurotoxic impact on human health [98]. Nonetheless, much emphasis is drawn to PVC and obviously less to PS, hence, the reason why the most important property of plastic feedstock is whether it contains PVC or not [99]. Thus, PVC's pyrolysis (thermal degradation) and its resulting products are different from those obtained from PE, PET, PS and PP. However, with reference to this same work by Arena and Mastellone [99], no report has been presented regarding a pyrolysis technology designated for a particular or specific type of plastic. Should a feedstock contain PVC, it is better if the plant contains a pre-treatment mechanism, say a solvent scrubber for the removal of $\mathrm{HCl}[100]$. Note that this is essential when dealing with a mixture of feedstocks and when the PVC is individually being treated. This is because of the limitation attached to this 
type of plastic due to its constituent undesirable halogen compounds, such as dioxins and toxins [39]. However, the van der Waals force, the force that binds molecules together and prevents them from collapsing, plays a significant role when it comes to the decomposition and complete reaction of any polymeric waste. For the decomposition of the polymeric chains of the feedstock to occur, the van der Waals forces, vibrational forces, must exceed the enthalpy of the constituent carbon-carbon bonds.

The quality of a feedstock is also crucial, as seen from the current processes being utilised in various plastic pyrolysis reactions. According to Gao [73], using a wrong/poor plastic feedstock quality can cause a range of problems, such as the blockage and heating effect of the reaction chamber under consideration. A wrong feedstock quality can involve a range of parameters, such as water and/or related moisture contents, and dirt among other contaminants. The need for a pre-treatment is imperative to overcome this, as discussed in Sections 1 and 2. When an erroneous feedstock is utilised, more energy or unanticipated energy is utilised in the pyrolysis, which will negatively impact the residence time of the entire process, ultimately. Significant among the negative impact on the residence time is the longer residence time, thereby slowing production levels and opposing the economic viability of the process/system. The nature of this drawback has a firm negative impact on industrial-scale applications.

\subsection{Plastic Pyrolysis Technology}

WPM and related waste plastic handling processes are not news in the present day. A work by Moses [38] highlighted that today's worldwide accepted technology regarding waste plastic disposal is incineration. Nevertheless, incineration has a vast amount of health and environmental issues, as mentioned in Section 1. However, further research has shown that there are other technologies worthy of the conversion of waste plastics into useful products. Steam cracking and gasification are among other reputable technologies to attain this, according to Pandey et al. [72], but pyrolysis continues to lead the way in all technologies, as reported by Al-Salem et al. [1], and as extensively discussed in this paper. Generally, each pyrolysis technology comprises three components and this is due to feedstock characterisation, as explained in Sections 2.1 and 4.1, and the desired product yield. The three components include the feeding system, pyrolysis reactor and separation/collection system [73]. These components are dependent on each other in a systematic chain of processes.

\subsubsection{Feeding System}

The feeding system is where air, moisture and other solid materials are capable of being separated from the rest of the waste plastic materials [101]. Thus, the feeding system is, at most times, considered as the very first stage of a pyrolysis mechanism. Commercial processes, heating and melting in the feeding system are essentially the first steps, considering that they enhance the material flow in and around the chamber of the pyrolysis reaction system. However, different reactors require different feeding approaches. The free-fall feeding system is one of the feeding approaches and this is believed to be common with fixed bed reactors. This is the case with fluidised beds as well. Inarguably, the free-fall feeding system is the feeding approach used with free-fall reactors, as demonstrated in a work carried out by Ellens [71], in their fast pyrolysis process of the reactor with HC wastes, and in another work conducted by Shoaib et al. [102]. The latter also utilised the feeding system in a fast pyrolysis process to produce bio-products, including oils. Nonetheless, most feeding systems utilise gravity, a free-fall facilitator or an aided extruder for the movement of melted plastics into the reactors. This is common with kiln reaction systems as well as free-fall reactors. The temperature gradient is significant in this case of pre-treatment, so that a certain type of feed is not over-heated and, thus, melted prior to entering the pyrolyser, as discussed in Sections 1 and 1.1. For instance, PS plastic types require a temperature gradient of $420^{\circ} \mathrm{C}$, and $250^{\circ} \mathrm{C}$ for PVC [101,103]. Furthermore, PET, LDPE and HDPE have their respective heating temperatures. 


\subsubsection{Pyrolysis Reactor}

Further to the 'Reactor Type' discussed in Section 2.2, a summarised discussion of the pyrolysis reactor is presented here. With reference to research conducted by Ali and Siddiqui [48], it was established that the reaction chamber was the central component of a pyrolysis system, a part they described to be highly functional as per controlled decomposition, homogenisation and outgassing in a single process.

Different reactors have varying operating temperatures. The variance ranges from $250{ }^{\circ} \mathrm{C}$ (Mazda fixed-bed catalytic process in Japan) to $800{ }^{\circ} \mathrm{C}$ (compact power fixed-bed pyrolysis in the U.K.) [92]. However, most pyrolysis reactors operate between $400{ }^{\circ} \mathrm{C}$ and $550{ }^{\circ} \mathrm{C}$, emphasised by [92], in their production of pyrolytic diesel and other fuels using waste plastics. Nonetheless, a $600{ }^{\circ} \mathrm{C}$ or higher temperature is recommended for plastic pyrolysis, but emphasis is laid on the type of reactor being a bubbling fluidised bed reactor [72]. The temperature sensors of the pyrolysis reactors are not installed at the same positions for the same reactor types. This is mainly the reason why reports from different studies using the same reactor type and feedstocks records different operating temperatures, as highlighted in a work carried out by Gao [73]. Retention time is also key to the pyrolysis technology in effect, and as explained in Section 2.4.

At operating temperatures above $800{ }^{\circ} \mathrm{C}$, gasification is attained, a cross-boundary of pyrolysis. Salaudeen et al. [41] utilised the gasification method to yield fuel and other valuable products with waste plastics as a source feed. In the experimental work carried out by Dou et al. [104], waste plastic was converted into hydrogen, the lightest element in the periodic table of the elements, with the aid of a gasification process. Hence, gasification products are mainly short hydrocarbons that remain gases under room temperature and atmospheric pressure.

\subsubsection{Separation and Collection System}

The separation and collection of the yield is not the last part of the output of plastic pyrolysis, but immensely influential to the overall process. Apparently, without this part, the pyrolytic process will be insignificant because the yield of the fuel or pyrolysis product is acquired at this stage for further decisions, including the characterisation, analytical analysis and use. Sophonrat et al. [90] used a two-step pyrolysis separation approach without further separation steps to produce and collect oxygenated compounds and high hydrocarbon products, including wax at $350{ }^{\circ} \mathrm{C}$ and $500{ }^{\circ} \mathrm{C}$ temperatures, respectively, with a source feed of PE and PS. The separation process may vary from plant to plant, with some yielding just liquid, gas and solid residues, while others perform the separation in a complete phase with the aid of distillation columns. Such mechanisms yield the products into unique factions based on temperature cuts. Since the yields can take a variety of forms (this is discussed in Section 3), how the system is set up for their separation and collection is significant to this. The complete or rather partial oxidation of materials guarantees energy recovery, as reported by Troitsch [105], hence, giving rise to the yielding of gaseous fuels, liquid oils, heat, power and char apart the from adjoining by-products that may tend to dispose of as ash. Plastic pyrolysis products mainly comprise of combustible gases and liquids. Regarding commercial processes, the quantity of pyrolytic gas yielded and their components play a pivotal role in product reclamation in the form of energy [3]. These gases also include non-combustible materials. Non-combustible gases are mainly constituted of HCs, a minor amount of $\mathrm{H}_{2}$ and $\mathrm{CO}$. However, these gases have $\mathrm{HHV}$ and can be liquefied as fuels or can directly be subjected to heating up the pyrolyser, if the amount is significant enough, thereby reducing the main/direct energy input [3], hence, fostering selfsustainability. Aside from this, it can be redirected into an incinerator, where it can be flared off with air [106]. Since ash may be present in these gases, many commercial processes incorporate a scrubber for cleaning the gases to free them from ash content. Figure 3 is a schematic diagram of the fuel production from mixed waste plastics assembly, a work carried out by Moses [38]. The collection system utilised in his work is a fractionation column and a condensation unit. The fuel was collected in a measuring cylinder with a 
chiller operating at a temperature of $5^{\circ} \mathrm{C}$, at which the vaporised steam was cooled into the liquid fuel.

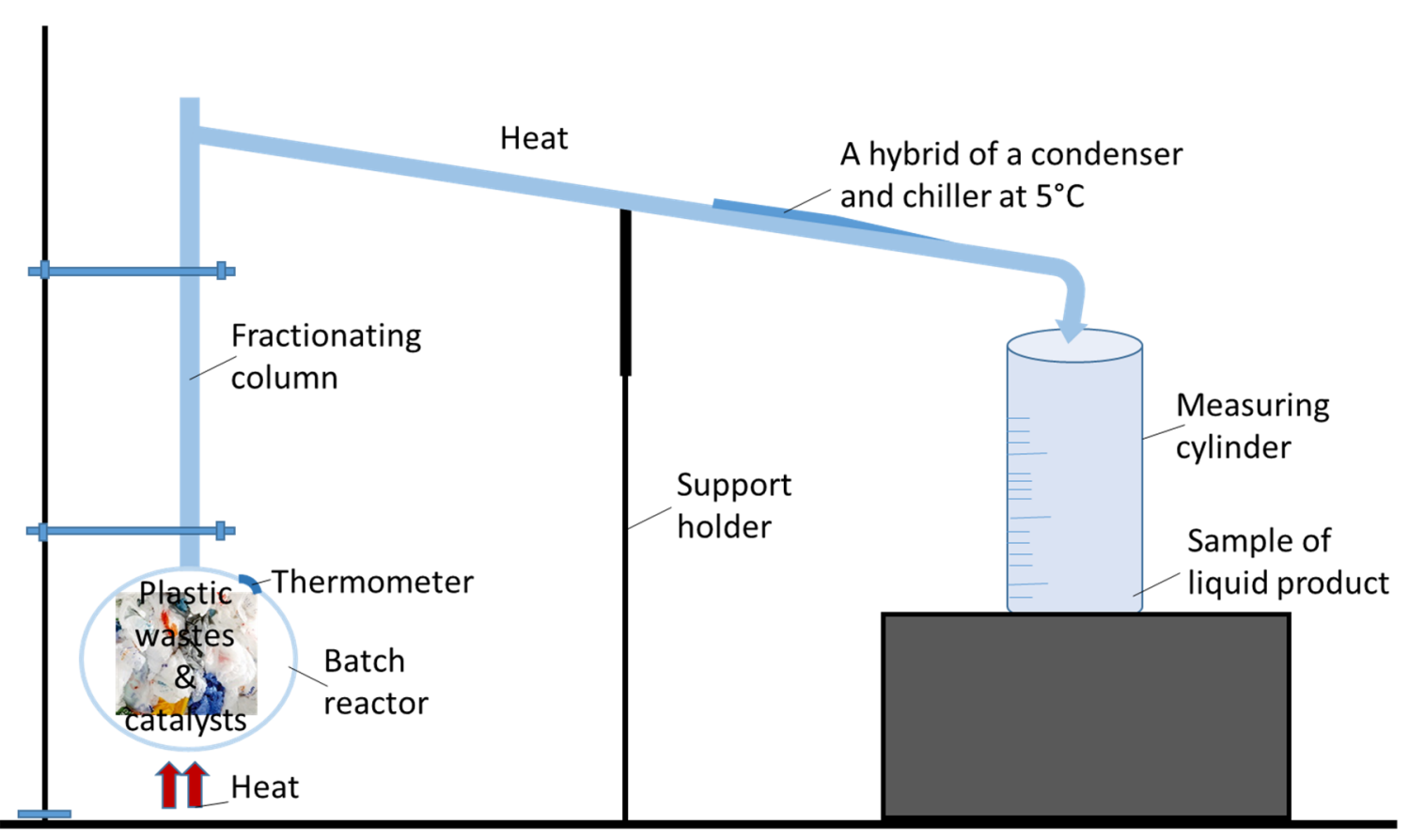

Figure 3. Schematic diagram of a fuel production assembly for mixed waste plastics (adapted from [38]).

By and large, liquid products can be combusted for power generation or, in other cases, further separated and refined to yield high-quality fuels and related useful materials.

\subsection{Practical Implications of This Literature}

The underlying practicalities of this review cover a range of benefits in the chemistry and chemical engineering fields, the environment, industrial-scale production and research supports, among other related implications. The review summarises a range of research, particularly on waste plastics and WPPs. It reveals some common gaps and misconceptions surrounding waste plastics pyrolysis and provides clear arguments against them. These misconceptions and gaps such as pyrolysis not being a sustainable solution to waste plastics and the idea that waste plastic is indeed wealth due to its potential of being converted into fuel and other useful materials, are challenges (current and/or future) embedded in this field. The growing interests surrounding pyrolysis have been uncovered and emphasised. The major limitations tied to thermal pyrolysis are discussed, and some necessary recommendations are offered, such as the construction of thermal pyrolysis plants near catalytic pyrolysis plants for an efficient and eco-friendly oil upgrade, and other valuable materials useful in the petrochemical industry and the wider world. This also favours the practical implications of this literature. Furthermore, this review paper aids the future work of other researchers in this field and enables them to reach meaningful conclusions.

The review has performed an extensive and detailed literature survey on WPTP, simplifying a bulk of research work into one paper, which can serve as a reference source for further studies. This recommendation will complement the current studies being conducted in this field, as well as provide a foundation for future research developments.

\section{Conclusions}

To date, we are well informed on the environmental challenges associated with waste plastics, stretching from landfilling problems through to pollution, including ocean pol- 
lution, and down to groundwater contamination. These challenges have continued to exponentially rise as per man's increased dependence on plastics for daily use owing to their lightweight, flexibility, moisture resistance, strength and relatively inexpensive quality. As such, an extensive literature review on WPTP was performed. Common misconceptions and research gaps surrounding this field were revealed, thereby setting the right technical platform for future research. This, among other results discussed in this paper, supports the new findings in this work. This literature review also shared a range of useful materials and valuable products associated with WPP, ensuring ease of access for future studies. Thus, the trending pace of pyrolysis continues to make substantial impacts on a range of industries, from medical to food and extending to the petrochemical world, as explored in this paper. For example, the sequential pyrolysis of MWP to acquire gasoline/petrol and diesel is crucial, as discussed in the introductory Section. This is an alternative to conventional gasoline and diesel and, thus, a boost to the creeping energy and power generation in developing countries around the world. Additionally, this serves as an assurance to the reports circulating around the world on the depletion of fossil fuel, the most common source of conventional gasoline and diesel, in the not-too-distant future. Furthermore, this paper investigated the fundamentals of co-pyrolysis with emphasis on plastics and biomass as feedstock. The significance of co-pyrolysis, such as its capability to improve the quality and quantity of pyrolysis oil, is also highlighted. With this distinct category of pyrolysis, similar to the case concerning the base pyrolysis (thermal pyrolysis), a range of petrochemical products are realistic depending on an array of operating factors, such as the type of pyrolysis reactor, reaction temperature and residence time, as thoroughly explained in Section 2. How these factors are utilised in WPTP are broadly reviewed, and the impacts they have on one another, as well as the reaction process in its entirety, are examined, and the subsequent products produced are also mentioned. Typical among these products is diesel fuel oil; a qualitative assessment of WPP and petroleum products with emphasis on diesel was investigated and some comparisons were made, as depicted in Section 3. In the commercial world for WPP, there are prominent process parameters involved. These process parameters were thoroughly examined, as depicted in Section 4 . Concerning the further work on WPP that is underway, these active commercial plastic pyrolysis processes and technologies remain firm foundations of and support to new research, especially in this chemical industry category.

Conclusively, pyrolysis gives rise to energy production and other useful products with waste plastics as feedstock, thereby favouring the circular economy and repositioning our environments to being friendly and breathtaking. However, another school of thought argues against this technology as a form that is not sustainable and, thus, not a solution to the problems of waste plastics. Nonetheless, this literature review disapproved this by exploring numerous works that disclaimed this by noting the enormous environmental advantages associated with pyrolysis as compared to other waste plastic recycling methods in line with their characteristic properties of not producing dioxins and having reduced $\mathrm{CO}$ and dioxide emissions.

The foremost limitations of this literature review include the optimisation of thermal pyrolysis, such as catalytic pyrolysis, the catalyst as an influential factor when it comes to WPP and catalysis in general. However, to stay in line with the objectives of this WPTP review, these factors were exempted.

Hence, the literature evidently identified key attainments in the field in recent years, including foremost research questions, gaps, the factors influencing the yields and future research needs, all of which are major aspects in pyrolysis in general and particularly WPTP. The review revealed itself as a detailed, sustainable and efficient recycling resource to treat waste plastics, thus expressing a firm assurance into the current foundations of pyrolysis. The growing interest in pyrolysis by researchers and industries was analysed. In conclusion, this review serves as a hub in which numerous other papers were summarised, with some substantial modifications and recommendations made. 
Author Contributions: O.Y.Y.: Writing-Original draft preparation. S.H.Z.: Review, editing and supervision. All authors have read and agreed to the published version of the manuscript.

Funding: This research received no external funding.

Institutional Review Board Statement: Not applicable.

Informed Consent Statement: Not applicable.

Data Availability Statement: Not applicable.

Acknowledgments: The first author, Osman Yusifu Yansaneh, wishes to acknowledge the Commonwealth Scholarships Commission for their continued sponsorship in his studies. Appreciations go to the University of Hull also for partnering in sponsoring his programme.

Conflicts of Interest: The authors declare no conflict of interest.

\section{References}

1. Al-Salem, S.M.; Antelava, A.; Constantinou, A.; Manos, G.; Dutta, A. A review on thermal and catalytic pyrolysis of plastic solid waste (PSW). J. Environ. Manag. 2017, 197, 177-198. [CrossRef] [PubMed]

2. PlasticsEurope. Plastics-The Facts 2014/2015. An analysis of European Plastics Production, Demand and Waste Data. PlasticsEurope, Association of Plastics Manufacturers. 2014. Available online: https://plasticseurope.org/wp-content/uploads/2021/1 0/2014-Plastics-the-facts.pdf (accessed on 9 September 2019).

3. Singh, R.K.; Ruj, B. Time and temperature depended fuel gas generation from pyrolysis of real world municipal plastic waste. Fuel 2016, 174, 164-171. [CrossRef]

4. Sophonrat, N.; Sandström, L.; Johansson, A.-C.; Yang, W. Co-pyrolysis of mixed plastics and cellulose: An interaction study by Py-GC × GC/MS. Energy Fuels 2017, 31, 11078-11090. [CrossRef]

5. Ma, J.; Shi, L.; Shi, Y.; Luo, S.; Xu, J. Pyrolysis of polymethylsilsesquioxane. J. Appl. Polym. Sci. 2002, 85, 1077-1086. [CrossRef]

6. Fivga, A.; Dimitriou, I. Pyrolysis of plastic waste for production of heavy fuel substitute: A techno-economic assessment. Energy 2018, 149, 865-874. [CrossRef]

7. Beti, D.R.; Ring, T.A. Programmed Temperature Pyrolysis: Alterations to the Standard Method; Energy and Geoscience Institute, the University of Utah: Salt Lake City, UT, USA; Department of Chemical Engineering, the University of Utah: Salt Lake City, UT, USA, 2019.

8. Encinar, J.; González, J.F.G. Pyrolysis of synthetic polymers and plastic wastes. Kinetic study. Fuel Process. Technol. 2008, 89, 678-686. [CrossRef]

9. Zafar, S.; Pyrolysis of Municipal Wastes. BioEnergy Consult Powering a Greener Future. Available online: https://www. bioenergyconsult.com/pyrolysis-of-municipal-waste/ (accessed on 27 November 2021).

10. Themelis, N.J.; Mussche, C. 2014 Energy and Economic Value of Municipal Solid Waste (MSW), Including Non-Recycled Plastics (NRP), Currently Landfilled in the Fifty States. Columbia University-Earth Engineering Centre. Advancing the Goals for Sustainable Waste Managements. Available online: https:/ /www.americanchemistry.com/Policy/Energy/Energy-Recovery/20 14-Update-of-Potential-for-Energy-Recovery-from-Municipal-Solid-Waste-and-Non-Recycled-Plastics.pdf (accessed on 16 July 2021).

11. Gershman, H.W.; Biofuel Opportunities for Solid Waste Management Systems. Gershman, Brickner \& Bratton, Inc. Fairfax, VA USA. 12 November, 2013. GBB-Quality-Value-Ethics-Results. 2013. Available online: http://gbbinc.com/wp-content/uploads/ 2013/06/GershmanRSB2013.pdf (accessed on 12 December 2020).

12. Al-Salem, S.M.; Lettieri, P.; Baeyens, J. Recycling and recovery routes of plastic solid waste (PSW): A review. Waste Manag. 2009, 29, 2625-2643. Available online: https://pubmed.ncbi.nlm.nih.gov/19577459/ (accessed on 29 September 2019). [CrossRef]

13. Kaminsky, W.; Predel, M.; Sadiki, A. Feedstock recycling of polymers by pyrolysis in a fluidised bed. Polym. Degrad. Stab. 2004, 85, 1045-1050. [CrossRef]

14. Williams, E.A.; Williams, P. Analysis of products derived from the fast pyrolysis of plastic waste. J. Anal. Appl. Pyrolysis 1997, 40-41, 347-363. [CrossRef]

15. Chen, D.; Yin, L.; Wang, H.; He, P. Pyrolysis technologies for municipal solid waste: A review. Waste Manag. 2014, 34, $2466-2486$. [CrossRef]

16. McKay, G. Dioxin characterisation, formation and minimisation during municipal solid waste (MSW) incineration: Review. Chem. Eng. J. 2002, 86, 343-368. [CrossRef]

17. Qinglan, H.; Chang, W.; Dingqiang, L.; Yao, W.; Dan, L.; Guiju, L. Production of hydrogen-rich gas from plant biomass by catalytic pyrolysis at low temperature. Int. J. Hydrogen Energy 2010, 35, 8884-8890. [CrossRef]

18. Buekens, A. Introduction to Feedstock Recycling of Plastics. In Feedstock Recycling and Pyrolysis of Waste Plastics; Scheirs, J., Kaminsky, W., Eds.; John Wiley \& Sons, Ltd.: Brussels, Belgium, 2006; pp. 3-41.

19. Figueroa, J.E.J.; Ardila, Y.C.; Hoss Lunelli, B.; Filho, R.M.; Wolf Maciel, M.R. Evaluation-of-pyrolysis-and-steam-gasificationprocesses-of-sugarcane-bagasse-in-a-fixed-bed. Chem. Eng. Trans. 2013, 32, 925-930. 
20. Williams, P.; Slaney, E. Analysis of products from the pyrolysis and liquefaction of single plastics and waste plastic mixtures. Resour. Conserv. Recycl. 2007, 51, 754-769. [CrossRef]

21. Miskolczi, N.; Ateş, F.; Borsodi, N. Comparison of real waste (MSW and MPW) pyrolysis in batch reactor over different catalysts. Part II: Contaminants, char and pyrolysis oil properties. Bioresour. Technol. 2013, 144, 370-379. [CrossRef]

22. Sharma, B.K.; Moser, B.R.; Vermillion, K.E.; Doll, K.M.; Rajagopalan, N. Production, characterisation and fuel properties of alternative diesel fuel from pyrolysis of waste plastic grocery bags. Fuel Process. Technol. 2014, 122, 79-90. [CrossRef]

23. Syamsiro, M.; Saptoadi, H.; Norsujianto, T.; Noviasri, P.; Cheng, S.; Alimuddin, Z.; Yoshikawaa, K. Fuel Oil Production from Municipal Plastic Wastes in Sequential. Energy Procedia 2014, 47, 180-188. [CrossRef]

24. Muhammad, C.; Onwudili, J.A.; Williams, P.T. Thermal Degradation of Real-World Waste Plastics and Simulated Mixed Plastics in a Two-Stage Pyrolysis-Catalysis Reactor for Fuel Production. Energy Fuels 2015, 29, 2601-2609. [CrossRef]

25. Fakhrhoseini, S.M.; Dastanian, M. Predicting pyrolysis products of PE, PP, and PET using NRTL activity coefficient model. $J$. Chem. 2013, 2013, 487676. [CrossRef]

26. Mastral, F.J.; Esperanza, E.; Garcia, P.; Juste, M. Pyrolysis of high-density polyethylene in a fluidised bed reactor. Influence of the temperature and residence time. J. Anal. Appl. Pyrolysis 2002, 63, 1-15. [CrossRef]

27. Butler, E.; Devlin, G.; Meier, D.; McDonnell, K. A review of recent laboratory research and commercial developments in fast pyrolysis and upgrading. Renew. Sustain. Energy Rev. 2011, 15, 4171-4186. [CrossRef]

28. Helt, J.E.; Agrawal, R.K.; Myles, K.M. Pyrolysis of Municipal Solid Waste. Annual Report, July 1984-June 1985, Argonne National Laboratory, ANL/CNSV-45, 1984. Available online: https:/ /www.osti.gov/biblio/7255421-pyrolysis-municipal-solid-wasteannual-report-july-june (accessed on 5 March 2021).

29. Demirbas, A. Pyrolysis of municipal plastic waste for recovery of gasoline range hydrocarbons. J. Anal. Appl. Pyrolysis 2004, 72, 97-102. [CrossRef]

30. Joo, H.S.; Guin, J.A. Continuous upgrading of a plastics pyrolysis liquid to an environmentally favorable gasoline range product. Fuel Process. Technol. 1998, 57, 25-40. [CrossRef]

31. Lee, K.-H.; Shin, D.-H. Characteristics of liquid product from the pyrolysis of waste plastic mixture at low and high temperatures: Influence of lapse time of reaction. Waste Manag. 2007, 27, 168-176. [CrossRef] [PubMed]

32. Marcilla, A.; Beltrán, M.; Navarro, R. Thermal and catalytic pyrolysis of polyethylene over HZSM5 and HUSY zeolites in a batch reactor under dynamic conditions. Appl. Catal. B Environ. 2009, 86, 78-86. [CrossRef]

33. Aguado, J.; Serrano, D.P.; Escola, J.M. Catalytic Upgrading of Plastic Wastes. In Feedstock Recycling and Pyrolysis of Waste Plastics, Scheirs, J., Kaminsky, W., Eds.; John Wiley \& Sons, Ltd.: Mostoles, Spain, 2006; pp. 73-110.

34. Blazso, M. Composition of Liquid Fuels Derived from the Pyrolysis of Plastics. In Feedstock Recycling and Pyrolysis of Waste Plastics; Kaminsky, J.S.A.W., Ed.; John Wiley \& Sons, Ltd.: Budapest, Hungary, 2006; pp. 315-344.

35. Demirbas, A. Effect of initial moisture content on the yields of oily products from pyrolysis of biomass. J. Anal. Appl. Pyrolysis 2004, 71, 803-815. [CrossRef]

36. McCaffrey, W.C.; Kamal, M.R.; Cooper, D.G. Thermolysis of polyethylene.pdf. Polym. Degrad. Stab. 1995, 47, 133-139. [CrossRef]

37. Indian Centre for Plastics in the Environment (ICPE) Newsletter. Management of Plastics, Polymer Wastes and Bio-Polymers and Impact of Plastics on the Eco-System. Envis Eco-Echoes. Volume 12, Issue 4, October-December 2011. Available online: http:/ /icpe.in/envis_newsletter/Envis-Eco-Echoes\%20Oct_Dec-2011(E\%20version).pdf (accessed on 2 January 2020).

38. Moses, K. Production and Characterization of Liquid Fuel from Mixed Plastic Wastes Using Catalytic Pyrolysis. Master's Dissertation, Makerere University, Kampala, Uganda, 2014

39. Marcilla, A.; Garcia-Quesada, J.C.; Sanchez, S.; Ruiz, R. Study of the catalytic pyrolysis behaviour of polyethylene polypropylene mixtures. J. Anal. Appl. Pyrol. 2005, 74, 38792. [CrossRef]

40. Abnisa, F.; Daud, W.M.A.W. A review on co-pyrolysis of biomass: An optional technique to obtain a high-grade pyrolysis oil. Energy Convers. Manag. 2014, 87, 71-85. [CrossRef]

41. Salaudeen, S.A.; Arku, P.; Dutta, A. Gasification of Plastic Solid Waste and Competitive Technologies. In Plastics to Energy: Fuel, Chemicals, and Sustainability Implications; Plastics Design Library; Elsevier: Amsterdam, The Netherlands, 2019 ; pp. $269-293$.

42. Wu, S.L.; Kuo, J.H.; Wey, M.Y. Thermaldegradation of waste plastics in a two-stage pyrolysis-catalysis reactor overcore-shell type catalyst. J. Anal. Appl. Pyrolysis 2019, 142, 104641. [CrossRef]

43. Kim, S. Pyrolysis kinetics of waste PVC pipe. Waste Manag. 2001, 21, 609-616. [CrossRef]

44. Mansur, D.; Simanungkalit, S.P.; Fitriady, M.A.; Safitri, D. Liquefaction of Plastic for Fuel Production and Application of Volcanic Ash as Catalyst. 2018. Available online: https://aip.scitation.org/doi/pdf/10.1063/1 (accessed on 17 September 2020).

45. Liu, Y.; Qian, J.; Wang, J. Pyrolysis of polystyrene waste in a fluidized-bed reactor to obtain styrene monomer and gasoline fraction. Fuel Process. Technol. 2000, 63, 45-55. [CrossRef]

46. López, A.; de Marco, I.; Caballero, B.; Laresgoiti, M.; Adrados, A. Influence of time and temperature on pyrolysis of plastic wastes in a semi-batch reactor. Chem. Eng. J. 2011, 173, 62-71. [CrossRef]

47. Dorado, C.; Mullen, C.A.; Boateng, A.A. Origin of carbon in aromatic and olefin products derived from HZSM-5 catalyzed co-pyrolysis of cellulose and plastics via isotopic labeling. Appl. Catal. B Environ 2015, 162, 338-345. [CrossRef]

48. Ali, M.F.; Siddiqui, M.N. Thermal and catalytic decomposition behaviour of PVC mixed plastic waste with petroleum residue. $J$. Anal. Appl. Pyrol. 2005, 74, 282-289. [CrossRef] 
49. Zhang, X.; Lei, H.; Chen, S.; Wu, J. Catalytic co-pyrolysis of lignocellulosic biomass with polymers: A critical review. Green Chem. 2016, 18, 4145-4169. [CrossRef]

50. Chen, W.; Shi, S.; Zhang, J.; Chen, M.; Zhou, X. Co-pyrolysis of waste newspaper with high-density polyethylene: Synergistic effect and oil characterization. Energy Convers. Manag. 2016, 112, 41-48. [CrossRef]

51. Guan, Y.; Ma, Y.; Zhang, K.; Chen, H.; Xu, G.; Liu, W.; Yang, Y. Co-pyrolysis behaviors of energy grass and lignite. Energy Convers. Manag. 2015, 93, 132-140. [CrossRef]

52. Uzoejinwa, B.B.; He, X.; Wang, S.; Abomohra, A.E.-F.; Hu, Y.; Wang, Q. Co-pyrolysis of biomass and waste plastics as a thermochemical conversion technology for high-grade biofuel production: Recent progress and future directions elsewhere worldwide. Energy Convers. Manag. 2018, 163, 468-492. [CrossRef]

53. Kositkanawuth, K.; Sattler, M.L.; Dennis, B. Pyrolysis of Macroalgae and Polysytrene: A Review. Curr. Sustain. Energy Rep. 2014, 1, 121-128. [CrossRef]

54. Zhao, Z.-Y.; Yan, H. Assessment of the biomass power generation industry in China. Renew. Energy 2012, 37, 53-60. [CrossRef]

55. Lopez, G.; Artetxe, M.; Amutio, M.; Bilbao, J.; Olazar, M. Thermochemical routes for the valorization of waste polyolefinic plastics to produce fuels and chemicals. A review. Renew. Sustain. Energy Rev. 2017, 73, 346-368. [CrossRef]

56. Yang, J.; Rizkiana, J.; Widayatno, W.B.; Karnjanakom, S.; Kaewpanha, M.; Hao, X.; Abudula, A.; Guan, G. Fast co-pyrolysis of low-density polyethylene and biomass residue for oil production. Energy Convers. Manag. 2016, 120, 422-429. [CrossRef]

57. Krerkkaiwan, S.; Fushimi, C.; Tsutsumi, A.; Kuchonthara, P. Synergetic effect during co-pyrolysis/gasification of biomass and sub-bituminous coal. Fuel Process. Technol. 2013, 115, 11-18. [CrossRef]

58. Miranda, R.; Yang, J.; Roy, C.; Vasile, C. Vacuum pyrolysis of PVC I. Kinetic study. Polym. Degrad. Stab. 1999, 64, 127-144. [CrossRef]

59. Li, W.; Cheng, C.; He, L.; Liu, M.; Cao, G.; Yang, S.; Ren, N. Effects of feedstock and pyrolysis temperature of biochar on promoting hydrogen production of ethanol-type fermentation. Sci. Total Environ. 2021, 790, 148206. [CrossRef] [PubMed]

60. Jung, K.-W.; Kim, K.; Jeong, T.-U.; Ahn, K.-H. Influence of pyrolysis temperature on characteristics and phosphate adsorption capability of biochar derived from waste-marine macroalgae (Undaria pinnatifida roots). Bioresour. Technol. 2016, 200, 1024-1028. [CrossRef] [PubMed]

61. Zhang, X.; Zhang, P.; Yuan, X.; Li, Y.; Han, L. Effect of pyrolysis temperature and correlation analysis on the yield and physicochemical properties of crop residue biochar. Bioresour. Technol. 2019, 296, 122318. [CrossRef] [PubMed]

62. Banik, C.; Lawrinenko, M.; Bakshi, S.; Laird, D.A. Impact of Pyrolysis Temperature and Feedstock on Surface Charge and Functional Group Chemistry of Biochars. J. Environ. Qual. 2018, 47, 452-461. [CrossRef] [PubMed]

63. Gai, X.; Wang, H.; Liu, J.; Zhai, L.; Liu, S.; Ren, T.; Liu, H. Effects of Feedstock and Pyrolysis Temperature on Biochar Adsorption of Ammonium and Nitrate. PLoS ONE 2014, 9, e113888. [CrossRef] [PubMed]

64. Hassan, M.; Liu, Y.; Naidu, R.; Parikh, S.J.; Du, J.; Qi, F.; Willett, I.R. Influences of feedstock sources and pyrolysis temperature on the properties of biochar and functionality as adsorbents: A meta-analysis. Sci. Total Environ. 2020, 744, 140714. [CrossRef] [PubMed]

65. Mandal, S.; Donner, E.; Vasileiadis, S.; Skinner, W.; Smith, E.; Lombi, E. The effect of biochar feedstock, pyrolysis temperature, and application rate on the reduction of ammonia volatilisation from biochar-amended soil. Sci. Total Environ. 2018, 627, 942-950. [CrossRef]

66. Zhao, X.; Zhan, L.; Xie, B.; Gao, B. Products derived from waste plastics (PC, HIPS, ABS, PP and PA6) via hydrothermal treatment: Characterization and potential applications. J. Chemosphere 2018, 207, 742-752. [CrossRef] [PubMed]

67. Brandrup, S.; Bittner, M.; Michaeli, W.; Menges, G. Recycling and Recovery of Plastics; Hansa Publishers: New York, NY, USA, 1996.

68. Sun, Y.; Gao, B.; Yao, Y.; Fang, J.; Zhang, M.; Zhou, Y.; Chen, H.; Yang, L. Effects of feedstock type, production method, and pyrolysis temperature on biochar and hydrochar properties. Chem. Eng. J. 2014, 240, 574-578. [CrossRef]

69. Mastellone, M.L.; Perugini, F.; Ponte, M.; Arena, U. Fluidized bed pyrolysis of a recycled polyethylene. Polym. Degrad. Stab. 2002, 76, 479-487. [CrossRef]

70. Della Zassa, M.; Favero, M.; Canu, P. Two-steps selective thermal depolymerization of polyethylene. 1: Feasibility and effect of devolatilization heating policy. J. Anal. Appl. Pyrolysis 2010, 87, 248-255. [CrossRef]

71. Ellens, C.J. Alternative Pyrolyzer Design: Free Fall Reactor. Iowa State University Center for Sustainable Environmental Technologies; 2021. Available online: https:/ / www.cset.iastate.edu/research/current-research/alternative-pyrolyzer-designfree-fall-reactor/ (accessed on 3 January 2020).

72. Pandey, U.; Stormyr, J.A.; Hassani, A.; Jaiswal, R.; Haugen, H.H.; Britt, M.E. Pyrolysis of Plastic Waste to Environmentally Friendly Products. In Energy Production and Management in the 21st Century IV; Moldestad University of South-Eastern Norway: Kongsberg, Norway, 2020; p. 61. [CrossRef]

73. Gao, F. Pyrolysis of Waste Plastics into Fuels. Ph.D. Thesis, University of Canterbury, Christchurch, New Zealand, 2010.

74. Jung, C.G.; Fontana, A. Production of Gaseous and Liquid Fuels by Pyrolysis and Gasification of Plastics: Technological Approach. Available online: https:/ / onlinelibrary.wiley.com/doi/10.1002/0470021543.ch10 (accessed on 14 September 2020).

75. Adrados, A.; de Marco, I.; Caballero, B.; López, A.; Laresgoiti, M.; Torres, A. Pyrolysis of plastic packaging waste: A comparison of plastic residuals from material recovery facilities with simulated plastic waste. Waste Manag. 2012, 32, 826-832. [CrossRef] [PubMed] 
76. Wang, G.; Li, Q.; Dzakpasu, M.; Gao, X.; Yuwen, C.; Wang, X.C. Impacts of different biochar types on hydrogen production promotion during fermentative co-digestion of food wastes and dewatered sewage sludge. Waste Manag. 2018, 80, 73-80. [CrossRef] [PubMed]

77. Freudenrich, C. How Plastics Work. 2007. Available online: https://science.howstuffworks.com/plastic2.htm (accessed on 7 January 2020).

78. Naresh, S.; Rockwell, J.; Huffman, G.P. Conversion of Waste Plastic to Oil: Direct Liquefaction versus Pyrolysis and Hydro-Processing; CFFLS, 533 S. Limestone St., University of Kentucky: Lexington, KY, USA, 1999.

79. Aguado, J.; Serrano, D.P.; Vicente, G.; Sánchez, N. Enhanced Production of $\alpha$-Olefins by Thermal Degradation of High-Density Polyethylene (HDPE) in Decalin Solvent: Effect of the Reaction Time and Temperature. Ind. Eng. Chem. Res. 2007, 46, 3497-3504. [CrossRef]

80. Ludlow-Palafox, C.; Chase, H.A. Microwave-induced pyrolysis of plastic wastes. Ind. Eng. Chem. Res. 2001, 40, 4749-4756. [CrossRef]

81. Miller, S.J.; Shah, N.; Huffman, G.P. Conversion of waste plastic to lubricating base oil. Energy Fuels 2005, 19, 1580-1586. [CrossRef]

82. Kaminsky, W. Pyrolysis with Respect to Recycling of Polymer ${ }^{\dagger}$. First Published: October 1995. Available online: https: / / onlinelibrary.wiley.com/doi/10.1002/apmc.1995.052320110 (accessed on 14 September 2020).

83. Ayhan, D. Effects of temperature and particle size on bio-char yield from pyrolysis of agricultural residues. J. Anal. Appl. Pyrolysis 2004, 72, 243-248. [CrossRef]

84. Tsai, W.; Lee, M.; Chang, Y. Fast pyrolysis of rice husk: Product yields and compositions. Bioresour. Technol. 2007, 98, 22-28. [CrossRef] [PubMed]

85. Sato, M.K.K.; Sakata, Y. Effect of pressure on thermal degradation of polyethylene. J. Anal. Appl. Pyrolysis 2004, 71, 569-589.

86. Chem.Fsu.Edu, (n.d). Gas Laws_Gay Lussac's Law. Available online: https://www.chem.fsu.edu/chemlab/chm1045/gas_laws. html (accessed on 5 July 2021).

87. Central Pollution Control Board (CPCB) Report. Material on plastic waste management. Parivesh Bhaham 2004, East Argum Nagar Delhi-110032. Available online: https://www.nswai.org/docs/An\%20Overview\%20of $\% 20$ Plastic $\% 20$ Waste $\% 20$ Management\%20by\%20CPCB.pdf (accessed on 14 September 2020).

88. Helmenstine, A. Gay-Lussac's Law-Definition, Formula, Examples. Available online: https://sciencenotes.org/gay-lussacslaw-definition-formula-examples/ (accessed on 5 July 2021).

89. Jung, S.-H.; Cho, M.-H.; Kang, B.-S.; Kim, J.-S. Pyrolysis of a fraction of waste polypropylene and polyethylene for the recovery of BTX aromatics using a fluidized bed reactor. Fuel Process. Technol. 2010, 91, 277-284. [CrossRef]

90. Sophonrat, N.; Sandström, L.; Zaini, I.N.; Yangaa, W. Stepwise Pyrolysis of Mixed Plastics and Paper for Separation of Oxygenatedand Hydrocarbon Condensates; Department of Materials Science and Engineering, KTH Royal Institute of Technology: Stockholm, Sweden, 2018. Available online: www.elsevier.com/locate/apenergy (accessed on 9 May 2021).

91. Gerpen, J.V. Diesel Combustion and Fuels. In Diesel Engine Reference Book, 2nd ed.; Challen, B., Baranescu, R., Eds.; Society of Automotive Engineers, Inc.: Warrendale, PA, USA, 1999.

92. Scheirs, J.; Kaminsky, W. Feedstock Recycling and Pyrolysis of Waste Plastics: Converting waste plastics into diesel and other fuels. In Wiley Series in Polymer Science; Scheirs, J., Ed.; John Wiley \& Sons, Ltd.: Milton, Australia, 2006.

93. Koppolu, L.; Agblevor, F.A.; Clements, L.D. Pyrolysis as a technique for separating heavy metals from hyperaccumulators. Part II: Lab-scale pyrolysis of synthetic hyperaccumulator biomass. Biomass-Bioenergy 2003, 25, 651-663. [CrossRef]

94. Zannikos, F.; Kalligeros, S.; Anastopoulos, G.; Lois, E. Converting Biomass and Waste Plastic to Solid Fuel Briquettes. J. Renew. Energy 2012, 2013, 360368. [CrossRef]

95. Zhou, C.; Yang, W. Effect of heat transfer model on the prediction of refuse-derived fuel pyrolysis process. Fuel 2015, 142, 46-57. [CrossRef]

96. Park, H.J.; Park, Y.K.; Dong, J.I.; Kim, J.S.; Jeon, J.K.; Kim, S.S.; Kim, J.; Song, B.; Park, J.; Lee, K.J. Pyrolysis characteristics of oriental white oak: Kinetic study and fast pyrolysis in a fluidized bed with an improved reaction system. Fuel Process. Technol. 2009, 90, 86-195. [CrossRef]

97. Aboulkas, A.; El harfi, K.; El Bouadili, A. Thermal degradation behaviours of polyethylene and polypropylene. Part I: Pyrolysis kinetics and mechanisms. Energy Convers. Manag. 2010, 51, 1363-1369. [CrossRef]

98. Sims, B. The Dangers of Polystyrene. Future Centre Trust. Available online: http://gracz-brand.com/en/life/4 (accessed on 14 February 2021).

99. Arena, U.; Mastellone, M.L. Fluidized Bed Pyrolysis of Plastic Wastes. In Feedstock Recycling and Pyrolysis of Waste Plastics; Kaminsky, J.S.a.W., Ed.; John Wiley \& Sons, Ltd.: Caserta, Italy, 2006; p. 440.

100. Zadgaonkar, A. Process and Equipment for Conversions of Waste Plastics into Fuels. In Feedstock Recycling and Pyrolysis of Waste Plastics; Kaminsky, J.S.a.W., Ed.; John Wiley \& Sons, Ltd.: Nagpur, India, 2006; pp. 709-728.

101. Bagri, R.; Williams, P.T. Catalytic of pyrolysis of polyethylene. J. Anal. Appl. Pyrolysis 2002, 63, 29-41. [CrossRef]

102. Shoaib, A.M.; El-Adly, R.A.; Hassanean, M.H.M.; Youssry, A.; Bhran, A.A. Developing a free-fall reactor for rice straw fast pyrolysis to produce bio-products. Egypt. J. Pet. 2018, 27, 1305-1311. [CrossRef]

103. Uemichi, Y.; Nakamura, J.; Itoh, T.; Sugioka, M.; Garforth, A.A.; Dwyer, J. Conversion of Polyethylene into Gasoline-Range Fuels by Two-Stage Catalytic Degradation Using Silica-Alumina and HZSM-5 Zeolite. Ind. Eng. Chem. Res. 1999, 38, 385-390. [CrossRef] 
104. Dou, B.; Wang, K.; Jiang, B.; Song, Y.; Zhang, C.; Chen, H.; Xu, Y. Fluidized-bed gasification combined continuous sorptionenhanced steam reforming system to continuous hydrogen production from waste plastic. Int. J. Hydrogen Energy 2016, 41, 3803-3810. Available online: www.sciencedirect.com (accessed on 1 August 2021). [CrossRef]

105. Troitsch, J. International Plastics Flammability Handbook; Hanser Publishers: Munich, Germany, 1990.

106. Okuwaki, A. Feedstock recycling of plastics in Japan. Polym. Degrad. Stab. 2004, 85, 981-988. [CrossRef] 